\title{
Reactor staging influences microbial community composition and diversity of denitrifying MBBRs- Implications on pharmaceutical removal
}

Torresi, Elena; Gülay, Arda; Polesel, Fabio; Jensen, Marlene Mark; Christensson, Magnus; Smets, Barth F.; Plósz, Benedek G.

Published in:

Water Research

Link to article, DOI:

10.1016/j.watres.2018.03.014

Publication date:

2018

Document Version

Peer reviewed version

Link back to DTU Orbit

Citation (APA):

Torresi, E., Gülay, A., Polesel, F., Jensen, M. M., Christensson, M., Smets, B. F., \& Plósz, B. G. (2018). Reactor staging influences microbial community composition and diversity of denitrifying MBBRs- Implications on pharmaceutical removal. Water Research, 138, 333-345. https://doi.org/10.1016/j.watres.2018.03.014

\section{General rights}

Copyright and moral rights for the publications made accessible in the public portal are retained by the authors and/or other copyright owners and it is a condition of accessing publications that users recognise and abide by the legal requirements associated with these rights.

- Users may download and print one copy of any publication from the public portal for the purpose of private study or research.

- You may not further distribute the material or use it for any profit-making activity or commercial gain

- You may freely distribute the URL identifying the publication in the public portal 


\section{Accepted Manuscript}

Reactor staging influences microbial community composition and diversity of denitrifying MBBRs- Implications on pharmaceutical removal

Elena Torresi, Arda Gülay, Fabio Polesel, Marlene M. Jensen, Magnus Christensson, Barth F. Smets, Benedek Gy. Plósz

PII: S0043-1354(18)30194-5

DOI: 10.1016/j.watres.2018.03.014

Reference: WR 13633

To appear in: Water Research

Received Date: 9 November 2017

Revised Date: 16 February 2018

Accepted Date: 6 March 2018

Please cite this article as: Torresi, E., Gülay, A., Polesel, F., Jensen, M.M., Christensson, M., Smets, B.F., Plósz, B.G., Reactor staging influences microbial community composition and diversity of denitrifying MBBRs- Implications on pharmaceutical removal, Water Research (2018), doi: 10.1016/ j.watres.2018.03.014.

This is a PDF file of an unedited manuscript that has been accepted for publication. As a service to our customers we are providing this early version of the manuscript. The manuscript will undergo copyediting, typesetting, and review of the resulting proof before it is published in its final form. Please note that during the production process errors may be discovered which could affect the content, and all legal disclaimers that apply to the journal pertain. 


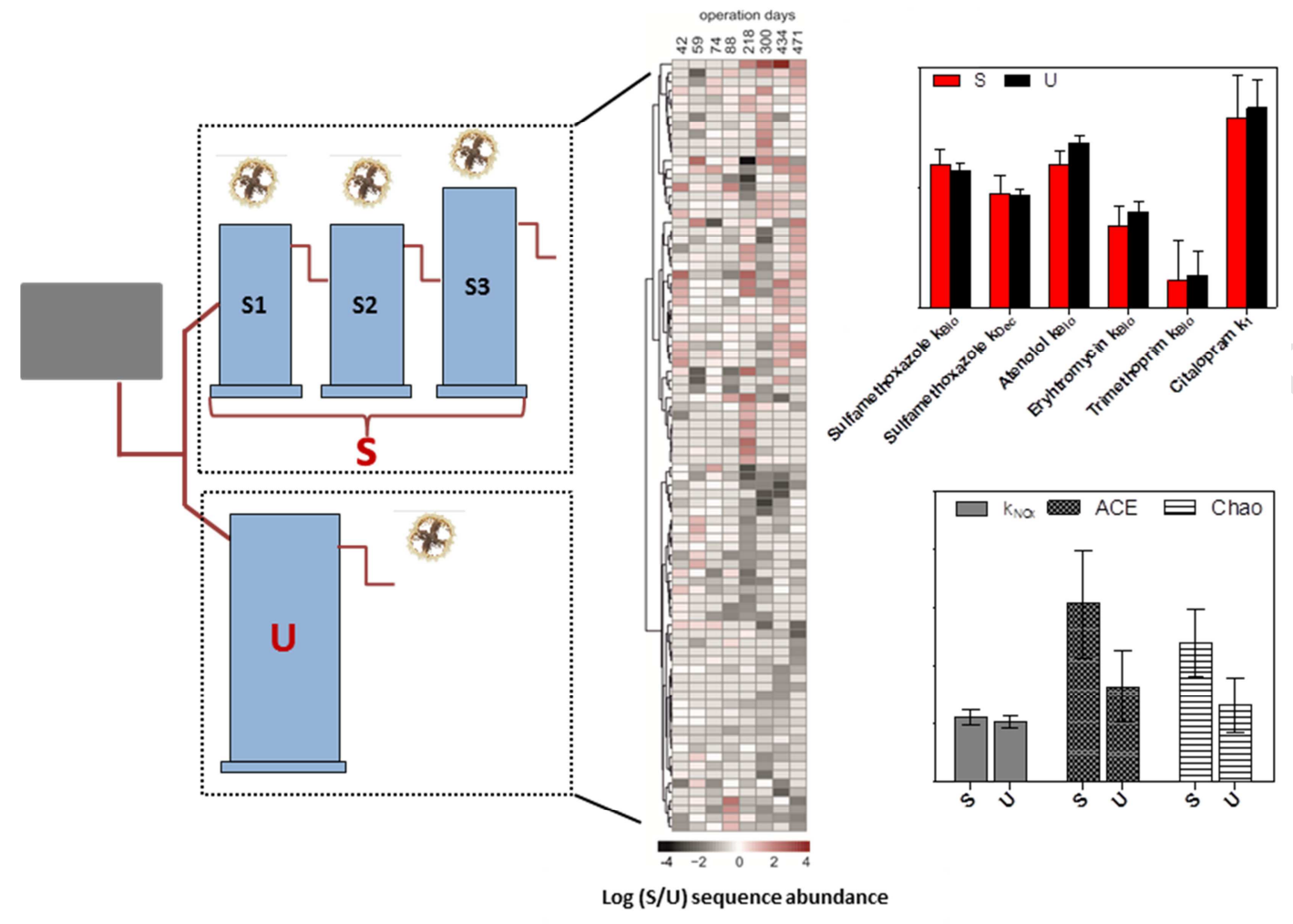




\section{Reactor staging influences microbial community}

\section{2 composition and diversity of denitrifying MBBRs-}

\section{Implications on pharmaceutical removal}

4 Elena Torresi ${ }^{1,2, * *}$, Arda Gülay ${ }^{1}$, Fabio Polesel $^{1}$, Marlene M. Jensen ${ }^{1}$, Magnus

5 Christensson ${ }^{2}$, Barth F. Smets ${ }^{1 *}$, Benedek Gy. Plósz ${ }^{1,3}$

6

$7 \quad{ }^{1}$ DTU Environment, Technical University of Denmark, Bygningstorvet B115, 2800 Kongens Lyngby,

8 Denmark

9 ㄹeolia Water Technologies AB, AnoxKaldnes, Klosterängsvägen 11A, SE-226 47 Lund, Sweden

$10 \quad{ }^{3}$ Department of Chemical Engineering, University of Bath, Claverton Down, Bath BA2 7AY, UK

11 "Corresponding authors: elto@env.dtu.dk, bfsm@env.dtu.dk 


\section{Abstract}

The subdivision of biofilm reactor in two or more stages (i.e., reactor staging) represents an option for process optimisation of biological treatment. In our previous work, we showed that the gradient of influent organic substrate availability (induced by the staging) can influence the microbial activity (i.e., denitrification and pharmaceutical biotransformation kinetics) of a denitrifying three-stage Moving Bed Biofilm Reactor (MBBR) system. However, it is unclear whether staging and thus the long-term exposure to varying organic carbon type and loading influences the microbial community structure and diversity. In this study, we investigated biofilm structure and diversity in the three-stage MBBR system (S) compared to a single-stage configuration (U) and their relationship with microbial functions. Results from 16S rRNA amplicon libraries revealed a significantly higher microbial richness in the staged MBBR (at 99\% sequence similarity) compared to single-stage MBBR. A more even and diverse microbial community was selected in the last stage of S (S3), likely due to exposure to carbon limitation during continuous-flow operation. A core of OTUs was shared in both systems, consisting of Burkholderiales, Xanthomonadales, Flavobacteriales and Sphingobacteriales, while MBBR staging selected for specific taxa (i.e., Candidate division WS6 and Deinococcales). Results from quantitative PCR (qPCR) showed that S3 exhibited the lowest abundance of 16S rRNA but the highest abundance of atypical nosZ, suggesting a selection of microbes with more diverse N-metabolism (i.e., notcomplete denitrifiers) in the stage exposed to the lowest carbon availability. A positive correlation $(p<0.05)$ between removal rate constants of several pharmaceuticals with abundance of relevant denitrifying genes was observed, but not with biodiversity. Despite the previously suggested positive relationship between microbial diversity and functionality in macrobial and microbial ecosystems, this 
34 was not observed in the current study, suggesting a need to further investigate structure-function 35 relationships for denitrifying systems.

36

37 Keywords: Moving Bed Biofilm Reactors, micropollutant removal, organic carbon, structure-function

38 relationships, heterotrophic denitrification

39 


\section{Introduction}

The presence of micropollutants (e.g., pharmaceutical and personal care products) in municipal wastewater effluent is well documented (Barbosa et al., 2016) and has been associated to several environmental risks (Painter et al., 2009).

Existing processes in conventional wastewater treatment plants (WWTPs) do not represent an efficient barrier against the release of micropollutants with treated effluent streams (Carballa et al., 2004). Hence, a number of engineering solutions are being explored to optimize the removal of micropollutants via biological wastewater treatment (Falås et al., 2016; Torresi et al., 2017, 2016).

The subdivision of biological reactors in two or more stages (i.e. reactor staging) has recently been proposed to enhance the removal of conventional pollutants (i.e., organic carbon, nitrogen) and pharmaceuticals in biofilm systems such as Moving Bed Biofilm Reactors (MBBRs) (Escolà Casas et al., 2015; Polesel et al., 2017). In MBBRs, biofilms grow on specifically designed plastic carriers, which are suspended and retained in the system (Ødegaard, 1999).

Due to presence of different fractions of organic carbon (e.g., from readily and slowly biodegradable to recalcitrant) in wastewater (Roeleveld and Van Loosdrecht, 2002), biofilm retained in different MBBR stages can be likely exposed to different substrate type and availability conditions. Based on long and short-term laboratory experiments, our previous work (Polesel et al., 2017) showed that the first stage of a pre-denitrifying three-stage MBBR system (S1) was effectively exposed to higher loadings of easily degradable organic carbon compared to the last stage (S3). Consequently, the first and last stage of the staged MBBR system exhibited, respectively, the highest and lowest denitrification and micropollutant biotransformation rate constant during targeted batch experiments (Polesel et al., 2017). However, it remains unclear: (i) if these differences in denitrification and biotransformation kinetics 
62 are related to the microbial community structure and diversity, induced by organic carbon availability; and (ii) if this results in major differences in the overall performance of three-stage MBBR system compared to a single-stage configuration.

Wastewater organic carbon availability has previously been shown to differently shape the structure and diversity of microbial communities of denitrifying (Xia et al., 2010), aerobic MBBR (Fu et al., 2010), and in aquifer sediment system ( $\mathrm{Li}$ et al., 2012, 2013), an effect that was found to correlate with micropollutants removal efficiency (Alidina et al., 2014). Hence, elucidating the microbial structure and diversity in biofilm systems and its influence on the overall microbial activity is fundamental for providing a basis to improve design and operation of MBBR systems towards pharmaceuticals removal. Additionally, although denitrification is a widespread process in biological wastewater treatment, substantial knowledge gaps remain concerning microbial communities under denitrifying condition (Lu et al., 2014).

Investigating microbial composition and diversity (i.e., $\alpha$-diversity) in biological systems appears especially important when assessing rare microbial functions, such as biotransformation of micropollutants (Helbling et al., 2015; Johnson et al., 2015a). The existence of a relationship between microbial diversity and activity has been debated but a positive relationship between biodiversity and ecosystem functionality is commonly accepted (Briones and Raskin, 2003). This relationship has been observed with respect to the biotransformation of several micropollutants in both full-scale (Johnson et al., 2015a) and laboratory- scale bioreactors (Torresi et al., 2016; Stadler at al., 2016), suggesting that communities with higher diversity are likely to have more functional traits (Johnson et al., 2015b). Accordingly, biofilms, potentially exhibiting more microbial niches and thus higher biodiversity than conventional activated sludge (Stewart and Franklin, 2008), can represent a valid option to enhance micropollutant removal. Furthermore, the exposure of biofilm to varying carbon types and conditions 
85 through bioreactor staging could additionally positively impact biofilm microbial diversity- the core

86

87

88

89

90

91

92

93

94

95

96

97

98

hypothesis tested herein.

In this study we evaluated the long-term effects of three-stage $(\mathrm{S}=\mathrm{S} 1+\mathrm{S} 2+\mathrm{S} 3)$ and single-stage configurations (U) of pre-denitrifying MBBR on the biofilm microbial community composition and diversity. High-throughput sequencing of 16S rRNA gene amplicon and quantitative PCR (qPCR) were used to assess microbial diversity at local (S1, S2, S3) and system (S, U) level and the abundance of relevant denitrifying genes, respectively. Thus, the main objectives of the study were:

1) to investigate the effect of organic carbon availability tiered by staging MBBRs on microbial composition and diversity at local and system level, benchmarked against a single-stage configuration;

2) to assess the dynamics in microbial community composition and denitrifying genes abundance in the two MBBR systems during long term operation;

3) to assess associations between micropollutant biotransformation, local/system diversity and denitrifying functionalities. 
99

100

101

102

103

104

105

106

107

108

109

110

111

112

113

\section{Methods}

\section{1. Continuous-flow operation of the MBBRs and batch experiments.}

A detailed description of the three- and single stage MBBR systems is given in Polesel et al. 2017. Briefly, two laboratory scale pre-denitrifying MBBR system with K1 carriers (AnoxKaldnes, Lund, Sweden) were operated in parallel under continuous-flow conditions for 1.5 years.

The single-stage system included a single bioreactor (U) with an operating volume of $6 \mathrm{~L}$. The threestage configuration included three reactors in series (S1, S2, S3) with a total operating volume of $6 \mathrm{~L}$ (1.5 L for S1 and S2 and $3 \mathrm{~L}$ for S3). The two systems were operated under identical conditions, i.e. influent flow rate, hydraulic residence time $(\mathrm{HRT}=8.9 \mathrm{~h})$, filling ratio $(33 \%)$, ambient temperature, medium characteristics (pre-clarified wastewater from Mølleåværket WWTP, Lundtofte, Denmark), influent nitrate concentration $\left(\sim 103 \mathrm{mgN} \mathrm{L}^{-1}\right)$, sparging of $\mathrm{N}_{2}$ gas for mixing and to ensure anoxic conditions (see Table S1 in Supplementary Information). The systems were started with MBBR carriers collected from the post-denitrification zone of Sjölunda WWTP (Malmö, Sweden), operated with external methanol dosing, as carbon source.

Two batch experiments were performed with the aim to assess denitrification rates and biotransformation rate constants of micropollutants at day 100 (Batch 1, after reaching a stable COD and nitrogen removal of ca. $70 \%$ and $44 \%$, respectively) and day 471 (Batch 2, at the end of the experiment) (Polesel et al., 2017). For the batch experiments, the flow to and between reactors was stopped and the reactors were drained. Subsequently, the reactors were filled with pre-clarified wastewater (grab sampled with an initial $\mathrm{NO}_{3}-\mathrm{N}$ concentration of $100-104 \mathrm{mgNL}^{-1}$ ) and carriers from U, S1, S2 and S3 (20\% and 10\% of filling ratio for Batch 1 and 2, respectively). The experiment lasted for 24 and $49 \mathrm{~h}$ for Batch 1 and 2, respectively, and 10 samples of aqueous solution were withdrawn 
for micropollutants analysis at regular intervals $(0,0.3,0.7,1.2,1.7,2.2,4.3,7.5$, and 10.3, $20 \mathrm{~h}$ for Batch 1 and additionally at $49 \mathrm{~h}$ for Batch 2). A fixed number of carriers was removed to maintain a constant filling ratio during batch experiments. The experiments were performed at ambient temperature (i.e., $20.3 \pm 0.05{ }^{\circ} \mathrm{C}$ in Batch 1 and $16.9 \pm 0.4{ }^{\circ} \mathrm{C}$ in Batch 2) and pH was adjusted to $8 \pm$ 0.5 with $1 \mathrm{M} \mathrm{HCl}$ spikes. Further details on the batch experiment can be found in Polesel et al. (2017).

\subsection{DNA extraction and quantitative PCR.}

To characterize microbial composition and its variation over long-term operation of the two MBBR systems, biofilm carriers for each MBBR were collected at day 0 (inoculum sample), 42, 59, 74, 88, $218,300,434$ and 471 of operation. Samples were collected with the highest frequency during the first 100 days of operation to assess biomass adaption to the new operational conditions (i.e., staged predenitrification without methanol addition). A prior analysis of biological replicates (2 different carriers) at day 0 showed that the biomass from one carrier provideed a sufficient descriptor of the entire community (results are discussed in section S1 of supplementary information and in Fig. S1). Each time, biomass was detached from one carrier using a sterile brush (Gynobrush, Dutscher Scientific) and sterile-filtered tap water, centrifuged (10000 rpm for 5 minutes), and the supernatant was removed. The sample was stored at $-20{ }^{\circ} \mathrm{C}$ until further analysis. DNA was extracted from attached biomass of one carrier using a Fast DNA spin kit for soils (MP Biomedicals, USA) following manufacturer's instructions. The quantity and quality of DNA were measured and checked by its 260/280 ratio by NanoDrop (Thermo Scientific ${ }^{\mathrm{TM}}$ ). Quantitative PCR (qPCR) was performed to estimate the abundance of total bacteria (EUB) with non-specific 16S rRNA gene targeted primers, and the abundance of a suite of genes encoding relevant functions: nitrate reductase (narG), cytochrome cd1 and copper nitrite reductases (nirK and nirS, respectively) nitrous oxide reductase of the Proteobacteria nos $Z$ variant 
(nosZ typical) and of the nos $Z$ variant (nos $Z$ atypical). Reported total microbial abundances are expressed as number of gene copies per gram of biomass. Primers and conditions for quantification of each gene are listed in Table S2.

\subsection{S rRNA gene amplification, sequencing and bioinformatic analysis.}

DNA extracted as described in 2.2 was also used for $16 \mathrm{~S}$ rRNA analysis by Illumina MiSeq. PCR amplification and sequencing were performed at the DTU Multi Assay Core Center (Kgs Lyngby, DK). Briefly, extracted DNA was PCR amplified using 16S rRNA bacterial gene primers PRK341F (5'CCTAYGGGRBGCASCAG-3') and PRK806R (5'-GGACTACNNGGGTATCTAAT-3')(Yu et al., 2005) targeting the V3 and V4 region. PCR products were purified using AMPure XP beads (Beckman-Coulter) prior to index PCR (Nextera XT, Illumina) and sequencing by Illumina MiSeq. Paired-end reads were assembled and screenings were implemented using mothur (Schloss, 2009). High quality sequences were then transferred to the QIIME environment and OTUs were picked at 93, 95, 97 and 99\% sequence similarity using the UCLUST algorithm with default settings, and representative sequences from each were aligned against the Silva123_SSURef reference alignment using SINA algorithm. Aligned sequences were then used to build phylogenetic trees using the Fast Tree method (Price et al., 2009).

Taxonomy assignment of each representative sequence at all similarity levels was implemented using the BLAST algorithm against the Silva128_SSURef database. Sequences with reference sequence hit below $90 \%$ were called unclassified.

Meta communities were created by combining OTU libraries of S1, S2 and S3 reactors and adding into the OTU tables of original and subsampled further to the lowest sample size. $\alpha$-diversity of OTU libraries was measured using the Chao1, Shannon, and ACE metrics as implemented in R using 
Phyloseq package. Microbial evenness was estimated as $\mathrm{H}_{1} / \mathrm{H}_{0}$ as described in Johnson et al. (2015a).

Distance matrices were constructed using the Bray-Curtis algorithms in R. Moving windows analysis was implemented using the microbial community of the inoculum as the reference point as described in Marzorati et al. (2008). Most abundant taxa and enriched taxa in S and U reactors were visualized using the Pheatmap package in R. The 100 most abundant taxa within the samples taken at 218, 300, 434, 471 days of operation were selected and compared.

\subsection{Denitrification in continuous-flow and batch experiments}

During continuous-flow operation, overall denitrification performance in the two MBBR systems was

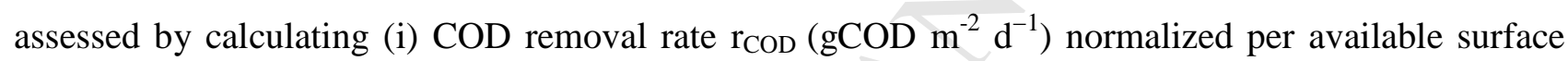
area (Table S1) in each reactor, based on measured influent and effluent COD concentration in each stage; (ii) the denitrification rate normalized to surface area of reactor $\mathrm{r}_{\mathrm{NOx}-\mathrm{N}}\left(\mathrm{gN} \mathrm{m}^{-2} \mathrm{~d}^{-1}\right)$, based on the measured influent and effluent concentration of $\mathrm{NO}_{\mathrm{X}}-\mathrm{N}$ (accounting for both $\mathrm{NO}_{3}-\mathrm{N}$ and $\mathrm{NO}_{2}-\mathrm{N}$; Sözen et al., 1998) in each stage. Measurements were taken semi-weekly during the first 100 days of operation to ensure stable start-up of the systems and semi-monthly subsequently.

During batch experiments, biomass-specific denitrification rates $k_{N O x}\left(\mathrm{mgN} \mathrm{g}^{-1} \mathrm{~d}^{-1}\right)$ were derived through linear regression of $\mathrm{NO}_{\mathrm{X}}-\mathrm{N}$ utilization curves for each sub-stage MBBR (Polesel et al., 2017). Specific denitrification rate at system level in $\mathrm{S}$ was calculated according to Eq. 1:

$k_{N O X, S}=\frac{k_{N O X, S 1} * X_{S 1} * V_{S 1}+k_{N O X, S 2} * X_{S 2} * V_{S 2}+k_{N O X, S 3} * X_{S 3} * V_{S 3}}{\sum X_{S M B B R} * V_{S}}$

Where $k_{N O x, S 1}, k_{N O x, S 2}, k_{N O x, S 3}, \quad\left(\mathrm{mgN} \mathrm{g}^{-1} \mathrm{~d}^{-1}\right)$ indicate specific denitrification rates in $\mathrm{S} 1, \mathrm{~S} 2 \mathrm{~S} 3$ respectively. $\mathrm{X}\left(\mathrm{g} \mathrm{L}^{-1}\right)$ and $\mathrm{V}(\mathrm{L})$ at the nominator in Eq. 1 indicate the biomass concentration and the 
volume of each MBBR stage, respectively, while $\mathrm{X}_{\mathrm{SMBBR}}\left(\mathrm{g} \mathrm{L}^{-1}\right)$ and $\mathrm{V}_{\mathrm{S}}(\mathrm{L})$ at the denominator are the biomass and volume of the staged system as a total MBBR (S).

\subsection{Micropollutants in continuous-flow and batch experiments}

Only indigenous pharmaceuticals occurring in municipal wastewater were quantified, as no reference pharmaceuticals were spiked during continuous-flow and batch experiments. Twenty-three pharmaceuticals were targeted and can be grouped in five categories: beta-blockers, sulfonamide antibiotics, anti-inflammatory drugs, psycho-active drugs, X-ray contrast media. The complete list of targeted pharmaceuticals quantified using HPLC-MS/MS analysis is reported in section S2 of the Supplementary Information.

Continuous-flow samples were taken in two separate monitoring campaigns before the execution of Batch 1 (100 days) and 2 (471 days) experiments. Removal efficiencies were calculated by measuring influent and effluent concentration in the two systems (Polesel et al., 2017).

During batch experiments three main micropollutant removal mechanisms were observed or hypothesized: (1) biotransformation, (2) retransformation to parent compounds (e.g.., deconjugation), and (3) enantioselective biotransformation (Ribeiro et al., 2013). Pseudo first-order transformation kinetics $\mathrm{k}_{\mathrm{Bio}}\left(1, \mathrm{~L} \mathrm{~g}^{-1} \mathrm{~d}^{-1}\right)$, retransformation rates $\mathrm{k}_{\text {Dec }}\left(2, \mathrm{~L} \mathrm{~g}^{-1} \mathrm{~d}^{-1}\right)$, biotransformation rate constant of enantiomer 1 and 2, $\mathrm{k}_{\text {bio, } 1}$ and $\mathrm{k}_{\text {bio,2, }},\left(3, \mathrm{~L} \mathrm{~g}^{-1} \mathrm{~d}^{-1}\right)$ were estimated as described in Polesel et al. (2017) using the Activated Sludge Model framework for Xenobiotics (ASM-X), accounting for sorption processes (Plósz et al., 2012).

Subsequently, the estimated $\mathrm{k}_{\mathrm{Bio}}$ and $\mathrm{k}_{\mathrm{Dec}}$ in each sub-reactor of the staged MBBR configuration (Table S3) were used to calculate the following kinetic parameters: 
(i) system-level biotransformation/retransformation rate for $\mathrm{S}$ for each micropollutant. As described for specific denitrification rate (Eq. 1), system-level $\mathrm{k}_{\mathrm{Bio}, \mathrm{S}}$ (and similarly $\mathrm{k}_{\mathrm{Dec}, \mathrm{S}}$ ) were calculated according to Eq. 2:

$$
k_{\mathrm{Bio}, \mathrm{S}}=\frac{k_{\mathrm{Bio}, \mathrm{S} 1} * X_{S 1} * V_{S 1}+k_{\mathrm{Bio}, \mathrm{S} 2} * X_{S 2} * V_{S 2}+k_{\mathrm{Bio}, \mathrm{S} 3} * X_{S 3} * V_{S 3}}{\sum X_{S M B B R} * V_{S}}
$$

(ii) collective rate constants of multiple pharmaceuticals (collective $\mathrm{k}_{\mathrm{BioS} 1}-\mathrm{k}_{\mathrm{DecS} 1}, \mathrm{k}_{\mathrm{BioS} 2}-\mathrm{k}_{\mathrm{DecS} 2}$, $\left.\mathrm{k}_{\mathrm{BioS} 3}-\mathrm{k}_{\mathrm{DecS} 3}, \mathrm{k}_{\mathrm{BioU}}-\mathrm{k}_{\mathrm{Dec}}\right)$ to compare the performance of each sub-stage of S MBBR with $\mathrm{U}$ MBBR in terms of micropollutant biotransformation. The rate collective rate constants of multiple pharmaceuticals were calculated using the multifunctionality measure described by Zavaleta et al. (2010) and Johnson et al. (2015a). Briefly, the rate constants of each pharmaceuticals were scaled (to a mean of 0 , standard deviation of 1 ) and the collective rate constants were obtained by averaging of the scaled rates.

\subsection{Analytical methods}

In all batch and continuous-flow samples, concentrations of conventional pollutants, i.e. $\mathrm{NO}_{3}-\mathrm{N}, \mathrm{NO}_{2}$ $\mathrm{N}, \mathrm{NH}_{4}-\mathrm{N}$, total and soluble COD (sCOD) were measured with Hach-Lange/Merck colorimetric kits followed by spectrophotometry, as previously described in Polesel et al. (2017). Wastewater fractionation and quantification of the organic carbon availability $\left(\mathrm{mg} \mathrm{L}^{-1}\right.$ of biodegradable COD with its two sub-fractions, i.e., readily (Ss) and slowly (Xs) biodegradable COD) was performed according to Roeleveld and Van Loosdrecht (2002) by combination with BOD-analysis and measure of total and soluble COD. Samples for micropollutants were analyzed using HPLC-MS/MS as described in Escolà Casas et al. (2015) and in Polesel et al., (2017). Briefly, $4 \mathrm{~mL}$ of aqueous samples were sampled and 

stored in glass vials with addition of $1.4 \mathrm{~mL}$ pure methanol (99.9\%, Merck Millipore). Samples were 233 frozen at $-20{ }^{\circ} \mathrm{C}$ prior analysis. For the analysis $1.5 \mathrm{~mL}$ of each sample were transferred to an HPLC 234 vial and centrifuged (6000 rpm, $10 \mathrm{~min}$ ). Subsequently, $100 \mu \mathrm{L}$ of internal standard solution was added 235 to $900 \mathrm{~mL}$ of the centrifuged samples solution. Samples were analyzed with an injected volume of 100 $236 \mu \mathrm{L}$. Information regarding targeted micropollutants, HPLC-MS/MS and mass spectrometry conditions, 237 limit of quantification and detection are shown in Escolà Casas et al. (2015).

2.7 Statistical analysis.

240 Correlation between $\mathrm{k}_{\mathrm{Bio}}$, $\mathrm{k}_{\mathrm{Dec}}$, collective rate constants $\mathrm{k}_{\mathrm{Bio}}-\mathrm{k}_{\mathrm{Dec}}$ and denitrification rates $k_{N O x}$, 241 biodiversity indices (Shannon, ACE, Chao and evenness indices), denitrifying gene abundance were 242 estimated using Graph Prism 5.0. The statistical methods comprise (i) one way analysis of variance 243 (ANOVA) with Bonferroni post-hoc test (significance level at $\mathrm{p}<0.05$ ); (ii) Pearson correlation analysis 244 ( $\mathrm{r}$ values reported) and adjusted p-values (two-tailed), and (iii) paired Wilcoxon test. Although the 245 Wilk-Shapiro test of normality may suggest a normal distribution $(\mathrm{p}<0.05)$ as the underlying 246 distribution for the obtained biotransformation rate constants, bias could occur due to the small sample 247 size (equal to 4). Pearson coefficients were reported as an indication of the strength of the association 248 between the targeted parameters and micropollutant biotransformation rate constants. 
249

\section{Results and discussion}

\subsection{Comparison of continuous-flow operation performance in S and U MBBR systems}

\subsubsection{Denitrification}

The loading of readily biodegradable $\left(\mathrm{S}_{\mathrm{S}}\right)$ and slowly biodegradable $\left(\mathrm{X}_{\mathrm{S}}\right)$ COD fractions in influent wastewater varied significantly through the experimental time (Fig. S2), with $\mathrm{X}_{\mathrm{S}}$ typically contributing to more than $50 \%$ of biodegradable COD (bCOD). Most of influent $\mathrm{S}_{\mathrm{S}}$ was utilized in the first stage $\mathrm{S} 1$ (on average $70 \%$, Fig. S3a), leading to lower carbon loadings in the following stages $(1.6 \pm 0.4,0.78 \pm$ $0.2,0.6 \pm 0.2 \mathrm{gCOD} \mathrm{d}^{-1}$ in S1, S2, S3 respectively, Polesel et al., 2017). A decrease in the surface-

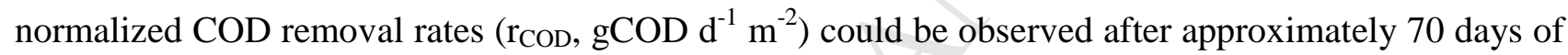
operation for the three-stage and the single-stage MBBR, due to differences in carbon loading (Fig. S2). No major differences in COD removal were observed between the two systems (Fig. 1a, (iii) $p=0.46$ with Wilcoxon test), with the exception of 3 sampling days when $r_{C O D}$ was up to 2-fold higher in the three-stage MBBR. Higher variability of performance was observed in terms of $\mathrm{NO}_{\mathrm{X}}-\mathrm{N}$ removal in the two systems (Fig. 1b). The three-stage MBBR generally outperformed the single-stage system (up to $30 \%$ higher, for $\sim 60 \%$ measurements) in terms of $\mathrm{r}_{\mathrm{NOx}-\mathrm{N}}$ after 50 days of operation, however the difference was found statistically insignificant $\left(\mathrm{p}=0.07\right.$, Wilcoxon test). Fluctuations in $\mathrm{r}_{\text {NOx-N }}$ were also caused by the variance in the influent bCOD. Biomass concentration rapidly increased in the first 100 days of operation (Fig. S4), reaching values (average \pm standard deviation) of $4.9 \pm 0.9,5.2 \pm 1.9$, $4.7 \pm 1.2,4.47 \pm 1.3 \mathrm{~g} \mathrm{~L}^{-1}$, for $\mathrm{S} 1, \mathrm{~S} 2, \mathrm{~S} 3$ and $\mathrm{U}$, respectively.

Overall, data during continuous-flow operation suggest an enhancement in denitrification performance in the three-stage MBBR, possibly explained based on reaction kinetics principles (Plósz, 2007), e.g., 
maximization of the uptake rate of $\mathrm{S}_{\mathrm{S}}$ and less degradable organic carbon in the stages of $\mathrm{S}$ configuration. Additionally, differences in nitrogen oxide reduction with a similar COD utilization were also observed during batch experiments, resulting in different calculated observable yield $Y_{H, o b s}$ $\left(\mathrm{mgCOD} \mathrm{mgCOD}^{-1}\right)$ in the four MBBRs (Polesel et al., 2017).

$<$ Fig. $1>$

\subsubsection{Micropollutant removal}

During continuous-flow operation, 11 of the 23 targeted compounds were detected in the pre-clarified wastewater, including compounds such as atenolol, citalopram, diclofenac, sulfamethoxazole, erythromycin and iohexol (Fig. $1 \mathrm{c}, \mathrm{d}$ ). During the two sampling campaigns (at $~ 100$ and 470 days of operation), atenolol and citalopram exhibited the highest removal efficiency ( $72 \%$ and 56-67\%, respectively, calculated according to Eq. S1), while the overall balance of sulfamethoxazole removal showed a net formation of parent chemicals $(>-150 \%)$ as a results of de-conjugation of human metabolites (Polesel et al., 2017). Overall, the removal efficiency of the measured pharmaceuticals was not significantly different between $U$ and S MBBR system in the two sampling campaigns ( $p>0.05$, Wilcoxon test in Fig. 1c and d), while diclofenac (DCF) presented higher removal in U ( 10\%) compared to S ( - 20\%).

\subsection{Microbial community composition and diversity in S and U MBBR systems}

\subsubsection{Microbial diversity at local and system level}

Microbial diversity in the two MBBR systems was assessed at 93\%, 95\%, 97\% and 99\% sequencing similarities cut-offs to maximize the resolution of the $\alpha$-diversity analysis between the four reactors. 
After the implementation of quality control measures, a total of 3178345 high quality sequences were obtained for each clustering, subsequently rarefied to 15800 sequences per sample. $\alpha$-diversity (expressed as Shannon diversity, ACE and Chao richness indices) increased overall with increasing sequence similarity cut-offs (Fig. 2), as expected (Birtel et al., 2015). As the two MBBR systems followed similar patterns over the time in terms of community diversity (Fig. 2), the $\alpha$ diversity was likely influenced by variations in influent wastewater composition in terms of COD and microbial community in the influent wastewater, as result of frequent change of the influent medium. Accordingly, linear regression analysis (Fig. S5) suggested a significant $(\mathrm{p}<0.05$, ANOVA) positive linear relationship between influent soluble COD with microbial richness (ACE and Chao) in $U$ ( $\mathrm{R}^{2}$ of $0.88, \mathrm{n}=6)$ and $\mathrm{S} 1\left(\mathrm{R}^{2}\right.$ of $\left.0.80, \mathrm{n}=6\right)$ at $99 \%$ similarity, but not for $\mathrm{S}, \mathrm{S} 2$ and $\mathrm{S} 3$.

\section{$<$ Fig. $2>$}

No major differences were observed in terms of Shannon diversity and evenness indices over time between S and U (Fig. 2), while ACE and Chao richness presented overall higher values in S compared to $\mathrm{U}$ (with increasing differences at increasing sequences similarity cut-offs, from $23 \%$ to $30 \%$ for $93 \%$ and 99 , respectively).

Furthermore, we assessed how the difference in the microbial community diversity in $S$ and $U$ ( $\beta$ diversity) changed over the duration of the experiment and estimated the time needed for the MBBR microbial communities to reach a steady composition that was dissimilar from the inoculum (Fig. 3). Moving window analysis (MWA) was implemented using the reciprocal of Bray-Curtis indices measured at different sequence similarities (Fig. 3). Microbial community similarity significantly decreased from the same inoculum sample during the first 200 days of operation, subsequently, reaching a relatively stable composition for the rest of the experiment. Bray-Curtis indices profiles (Fig. 3) for $\mathrm{S}$ and $\mathrm{U}$ decreased to the highest extent at $99 \%$ sequence similarity cut-off. 
As the MBBR microbial communities and the degree of dissimilarity from the inoculum community appeared stable after approximately 200 days of operation based on MWA, the Shannon, richness and evenness indices were averaged after 200 days of operation $(n=4)$ to assess statistical difference between the two systems and for each sub-stage of S (Fig. 4). For all four tested sequence similarity levels, no significant difference was observed for the Shannon diversity and evenness for the microbial communities prevailing in S and $\mathrm{U}$ (reported at 97 and 99\%, Fig. 4a-b). On the other hand, microbial richness (ACE and Chao) was higher in $\mathrm{S}$ than to $\mathrm{U}$ at both sequence similarities (at system level), with significant difference at 99\% sequence similarity cut-off (ANOVA, p<0.05, Fig. 4d).

<Fig.3>

Hence, our findings (Fig. 2 and Fig. 4) suggest that the exposure of microbial communities to a gradient of organic carbon availability, achieved through reactor staging, results in significantly higher microbial richness compared to a single-stage configurations. Additionally, average Shannon diversity, evenness and richness were higher (although not significantly different, ANOVA, p>0.05) in S3 compared to S1 and S2 at $99 \%$ sequence similarity (Fig. 4). It is likely that the more refractory and slowly biodegradable carbon, to which S3 was exposed during continuous-flow operation (Fig. S3), led to the co-existence of a more diverse microbial community due to substrate competition (Huston, 1994). On the contrary, the easily degradable carbon mostly utilized in S1 may have favoured microbial groups that dominate the microbial community.

Similar observations were previously reported in managed aquifer recharge systems (MAR), where higher community diversity was observed at more oligotrophic depths compared to the depths where more easily degradable carbon was available ( $\mathrm{Li}$ et al., 2013, 2012). Increased taxonomic richness was also associated with lower influent ambient nitrogen and carbon availability in full-scale wastewater treatment plant microbial communities (Johnson et al., 2015b). Conversely, higher microbial diversity 
(expressed as Shannon index) was found in the first stage of an aerobic two-stage nitrifying MBBR treating landfill leachate (Ciesielski et al., 2010).

$<$ Fig.4>

\subsubsection{Temporal variability in the selection of taxa by substrate availability in $S$ and $U$ MBRR systems}

We further investigated the development of microbial structure in S and U over 471 days of operation to elucidate whether staging the MBBR system resulted in a selection of specific taxa. Hence, we computed heatmaps of the 100 most abundant OTUs at order level sorted by most abundant OTUs after 200 days of operation (218, 300, 434, 471 days) (Fig. 5 (a) and (b)). In both systems, the methanolutilizing bacteria Methylophilales that were enriched in the inoculum (methanol dosing was applied to full-scale WWTP) decreased over time, eventually disappearing after approximately 200 days. A core of OTUs was shared in both systems, consisting of Burkholderiales, Xanthomonadales, Flavobacteriales and Sphingobacteriales. Burkholderiales (isolated from different environmental sources) has been shown to be able to biotransform a vast array of aromatic compounds (Pérez-Pantoja et al., 2012), as well as to be enriched by using methanol as carbon source (Kalyuzhnaya et al., 2008). Bacterial strains affiliated to the order Burkholderiale, Xanthomonadales and Sphingobacteriales were previously identified in a four-stage MBBR with a pre-denitrification configuration (Villemur et al., 2015) and they were suggested to play an important role in the biofilm development, due to excretion of exopolymeric substances (EPS) for biofilm formation (Pal et al., 2012). Flavobacteriales and Burkholderiales were associated to the biotransformation of venlafaxine and ranitidine, respectively, in WWTP community (Helbling et al., 2015). Notably, taxa such as AKYG1722, Caldilineales, JG30-KFCM45 and Candidate division WS6 were enriched in both MBBR systems during 300 days of operation. To effectively identify the microbial organisms that were differently selected in the two 
configurations, we considered the most abundant OTUs of S and U MBBRs and reported the log of the ratio of the sequence abundance in $\mathrm{S}$ and $\mathrm{U}(\log (\mathrm{S} / \mathrm{U}))$ (Fig. $5(\mathrm{c}))$. A similar approach was used for the taxa in S3 and S1 $(\log (\mathrm{S} 3 / \mathrm{S} 1)$, Fig. 5 (d)). Notably, the three-stage MBBR (S) selected for the OTU Bifidobacteriales and Candidate division WS6 after day 218. Candidate division WS6 have been previously identified as abundant community members in anoxic/anaerobic environments of hydrocarbon-and chlorinated-solvent-contaminated aquifer (Dojka et al., 1998, 2000). Candidate division WS6 and Deinococcales were enriched in S3 over S1 (Fig. 5 (4)), suggesting a correlation of these OTUs with low readily biodegradable carbon availability in S3 during continuous-flow operation. This is in disagreement with Dojka et al. (2000) that observed Candidate division WS6 mainly in organic-rich, anaerobic redox environment. The family Deinococcaceae is widely studied, since organisms from this groups have been observed to exhibit remarkable resistance to radiation (Chaturvedi and Archana, 2012). Conversely, Dictyoglomales, Microgenomates_4 and subgroup 4 of Acidobacteria were mostly enriched in $\mathrm{U}$ over $\mathrm{S}$ after 218 days (Fig. 5 (3)). Compared to other subgroups, the abundance of Acidobacteria subgroup 4 has been negatively associated with organic carbon availability and C-to-N ratio in grassland soils (Naether et al., 2012).

Overall, we observed generally dynamic microbial communities, with only few taxa consistently enriched after 218 days in the three-stage configuration compared to single-stage one. Considering the long-term operation of the two systems with actual pre-clarified wastewater influent, it is likely that (besides the organic substrate availability) continuous and random immigration by the microbial community present in the influent wastewater played an important role in shaping the microbial communities. The importance of microbial immigration was shown by calibrating a neutral model community assembly with dynamic observations of wastewater treatment communities (Ofiteru et al., 2010), in full-scale WWTP (Wells et al., 2014), as well as in a pilot-scale membrane bioreactor system 
385 (Arriaga et al., 2016). Additionally, cross-inoculation between staged reactors may have been occurred, 386 as previously observed in staged bioprocesses in full-scale WWTP (Wells et al., 2014).

$<$ Fig. 5> 


\subsubsection{Microbial and denitrifying gene abundance in $S$ and $U$ MBBR systems}

Quantification of 16S rRNA (total bacteria) and denitrifying genes was performed to investigate differences in denitrifying microbial communities in the four MBBR reactors (Fig. S6). For the U and S1 MBBR, microbial abundance of total bacteria during 471 days of operation could be associated with the influent substrate concentration - expressed as influent soluble COD (Fig. S7, $\mathrm{R}^{2}$ of 0.8 and 0.5, respectively). Conversely, no association was found for S2 and S3 with respect to influent sCOD.

As informed by moving window analysis, $\mathrm{APCR}$ data for all reactors were averaged from the point when the microbial community was stable (i.e., after 200 days of operation) (Table 1). The lowest $(\mathrm{p}<0.05)$ abundance of $16 \mathrm{~S}$ rRNA gene (copies $\mathrm{g}_{\text {biomass }}{ }^{-1}$ ) was measured in S3, mostly adapted to carbon limitation during continuous-flow operation, as previously observed in simulated managed aquifer recharge (Li et al., 2013). Overall, the measured nirS gene fraction was up to 10 times higher than $\operatorname{nirK}$ (in agreement with other studies in aquatic ecosystems, e.g., Braker et al., 2000; ), while no differences were observed between the four reactors in terms of nirS gene fraction (Table 1). Previous studies have suggested lower densities of nirK-containing denitrifiers in aquatic ecosystems (Braker et al., 2000). The decrease of nirS from the inoculum sample (day 0), adapted to methanol (Fig. S6) is consistent with the previous observation that utilization of methanol as a readily biodegradable substrate can select for nirS-expressing denitrifiers (Hallin et al., 2006). Furthermore, a change to different carbon sources can result in a loss of nirS density (Hallin et al., 2006). The S3 reactor was continuously exposed to the lowest $\mathrm{C}$-to- $\mathrm{N}$ influent ratio (average values of $\mathrm{C}$, expressed as SCOD, -to-N ratio of 1 , 0.8 and 0.7 for $\mathrm{S} 1$ and $\mathrm{U}, \mathrm{S} 2, \mathrm{~S} 3$ respectively), and previous research reported increased $\mathrm{N}_{2} \mathrm{O}$ production at lower C-to-N ratios ( Zhang et al., 2016). However, S3 exposed to lower C-to-N ratios during continuous-flow operation exhibited the highest $(\mathrm{p}<0.05)$ abundance of atypical nos $Z$ gene and a 
lower nitrite reductase and nitrous reductase ration (Table 1), which could indicate a more effective

$411 \mathrm{~N}_{2} \mathrm{O}$ removal with respect to other reactor stages. Furthermore, S3 and S1 had the highest and lowest 412 ratio of atypical to typical nosZ, respectively (Table 1). Typical nosZ genes have been associated with 413 bacteria capable of complete denitrification (thus encoding all the enzymes for converting nitrate to 414 nitrogen) (Sanford et al., 2012). In contrast, atypical nos $Z$ genes were also found in non-denitrifying 415 bacteria with more-diverse N-metabolism (e.g., missing nirK and nirS) (Orellana et al., 2014; Sanford 416 et al., 2012), and are commonly present at concentrations higher than typical nosZ in soil (Orellana et 417 al., 2014). Hence, our results suggest a microbial selection driven by the substrate gradient through the 418 MBBR stages, where most of the complete denitrifiers (carrying typical nosZ) are selected in S1 (with 419 the highest readily biodegradable substrate availability). On the other hand, microbes with more diverse $420 \mathrm{~N}$-metabolism (carrying atypical nosZ) are selected in S3. Although, based on prior reports, the highest $421 \mathrm{~N}_{2} \mathrm{O}$ production was expected in MBBR stages with low influent C-to- $\mathrm{N}$ ratio, the selection of nondenitrifying bacteria containing atypical nos $Z$ genes (which code for high affinity $\mathrm{N}_{2} \mathrm{O}$ reductase) may well imply a reduced accumulation of nitrous oxide. This factor suggests biofilm reactor staging as a 424 process optimisation means to reduce $\mathrm{N}_{2} \mathrm{O}$ emissions through wastewater treatment, which requires 425 further research. 
3.3. Linking activity, community composition and diversity with micropollutant biotransformation in batch experiments

\subsubsection{System level (S and $U$ )}

Based on the results of the batch experiments, biotransformation rate constants of the pharmaceuticals were calculated at system level for the three-stage MBBR system (Eq. 2) and compared with rate constants for the single-stage system for Batch 1 (Fig. S11) and Batch 2 (Fig. 6 a). We did not observe a significant difference in specific denitrification rate at system level (calculated as in Eq. 1) but higher $(\mathrm{p}<0.05)$ microbial richness was measured in $\mathrm{S}$ compared to $\mathrm{U}$ in Batch 2 (Fig. 6b). Nonetheless, no significant difference was observed in the biotransformation of the targeted micropollutants between the two MBBR systems (Fig S11 and Fig. 6a).

<Fig. 6>

\subsubsection{Local level (S1, S2, S3 and U)}

As reported in Polesel et al., 2017, the decreasing loading and availability of carbon during continuous-flow operation led to a decreasing trend of pharmaceuticals biotransformation from S1 to S3 (Table S3).

Pearson's coefficients $\mathrm{r}$ were used to evaluate associations between biotransformation rate constant $\mathrm{k}_{\mathrm{Bio}}$ $/ \mathrm{k}_{\text {Dec }}$ and (i) biodiversity indices (at $99 \%$ sequence similarity, Fig. S9); (ii) denitrifying gene abundance (Fig. S6); (iii) specific denitrification rates $\bar{k}_{\text {NoX }}\left(\mathrm{mgN} \mathrm{g}^{-1} \mathrm{~d}^{-1}\right)$ (Table S3). Only relevant $\mathrm{k}_{\mathrm{Bio}}$ and $\mathrm{k}_{\text {Dec }}$ values $\left(>0.1 \mathrm{~L} \mathrm{~g} \mathrm{~g}^{-1} \mathrm{~d}^{-1}\right.$ and corresponding to a removal $>20 \%$ according to the classification presented in Joss et al., 2006) were included in the analysis. Notably, correlations were performed by using only taxonomic diversity (based on $16 \mathrm{~S}$ rRNA amplicon sequencing), rather than data combining functional 
diversity (based on the phenotypes inferred from taxonomic descriptors and on mRNA sequencing), which was beyond the scope of this study. Although it has been observed that taxonomic and functional diversity associate with each other in wastewater treatment systems (Johnson et al., 2015b), additional information could be derived by the combination of both analyses.

In Batch 1, only few positive correlations $(\mathrm{p}<0.05)$ were observed between diversity indices and biotransformation rate constants of pharmaceuticals. i.e., sulfamethoxazole, trimethoprim and metoprolol (Fig. S10). In Batch 2, $\mathrm{k}_{\mathrm{Bio}}$ and $\mathrm{k}_{\mathrm{Dec}}$ of most detected pharmaceuticals were negative or not significantly correlated with microbial richness (Fig. 7), but positively correlated $(p<0.05)$ with specific denitrification rates $\mathrm{k}_{\mathrm{NOx}}$. The obtained correlations are reported in Fig. S8. Positive correlations $(\mathrm{p}<0.05)$ were found with $\mathrm{k}_{\mathrm{Bio}}$ of erythromycin, trimethoprim and collective pharmaceuticals as well as with the abundance of denitrifying genes narG, nirS, and nosZ typical, but not atypical nosZ.

The difference in the results between Batch 1 and 2 may stem from the variation in the denitrification rates $\mathrm{k}_{\mathrm{NOX}}$ obtained during batch experiment, that affected the cometabolic biotransformation of the pharmaceuticals (Polesel et al., 2017). Due to lower biotransformation rate constants obtained in Batch 2 compared to Batch 1, adaption of the biomass to targeted pharmaceuticals is unlikely. Previous studies on soil and wastewater activated sludge concluded that pre-exposure of the biomass to trace organic chemicals may not affect the removal efficiency of micropollutants (Falås et al., 2016) neither the microbial community structure nor its function (analyzed by metagenomes) (Alidina et al., 2014). As discussed previously, a stable microbial community was observed only after 200 days of operation and results from Batch 2 (at 471 days) may be considered representative of the long-time operation of the two MBBR systems.

Biotransformation of several micropollutants has been related to the lack of specificity of enzymes such as ammonia monooxygenase (Khunjar et al., 2011; Sathyamoorthy et al., 2013). To our knowledge, 
cometabolism of micropollutants by respiratory denitrifying enzymes (e.g., narG, nirS, nor, nosZ) has not been documented. Thus, the unexpected association between denitrifying genes and biotransformation of micropollutants may be the result of a genuine but nevertheless non-causal relationship (Johnson et al., 2015c). Further research is required to examine the cause of this correlation.

As mentioned previously, positive relationships between microbial diversity (and in particular $\alpha$ diversity) and biotransformation rate constants of micropollutants have been observed in activated sludge (Johnson et al., 2015a), in sequencing batch lab-reactors (Stadler and Love, 2016) and in nitrifying MBBRs (Torresi et al., 2016). Yet, similar negative correlation has been observed between biodiversity and removal of natural and synthetic estrogens in suspended biomass (Pholchan et al., 2013; Tan et al., 2013) and for sulfonamide antibiotics (sulfadiazine, sulfamethoxazole, sulfamethizole) in nitrifying MBBRs (Torresi et al., 2016). Among others, two phenomena may explain the lack of an observable (positive) relationship:

(i) A positive relationship between biodiversity (or richness) would emerge (a) if the microbial community consisted of a number of microorganisms with unique niche partioning or (b) if facilitative interactions (i.e., complementarity effects) occurred (Cardinale, 2011) . However, functional redundancy (i.e., different taxa coexist to perform the same functionality) could be sufficient to mask this positive interaction (Johnson et al., 2015b). Accordingly, if the biotransformation of a specific compound is performed by a large number of taxa, the increase of biodiversity may not necessary positively impact the biotransformation as it is not limited by the number of taxa that can perform it (Stadler and Love, 2016). Taken together, the negative correlation observed in this study between biotransformation rate constants and biodiversity, combined with the positive correlation 
with kinetics of denitrification, could suggest a redundancy of the denitrifying microbial community towards the biotransformation of these targeted pharmaceuticals.

This observation might further suggest that denitrifying systems exhibit higher biotransformation rates of pharmaceuticals compared to aerobic systems, due to the higher number of taxa performing this function. Hence, we compared the average biotransformation rate constants obtained in this study (under pre-denitrification conditions) and in post-denitrification MBBRs (Torresi et al., 2017) with kinetics obtained for aerobic nitrifying MBBRs (Torresi et al., 2016) (Fig. S12). While we observed comparable biotransformation kinetics for aerobic and pre-denitrifying MBBRs (this study) (Fig. S12a), post-denitrifying MBBRs indeed exhibited higher biotransformation rate constants for more than $60 \%$ of the examined pharmaceuticals (Fig. S12b) compared to aerobic MBBRs. In the post-denitrifying MBBRs (Torresi et al., 2017), additional carbon sources (i.e., methanol or ethanol) were dosed in the systems, which are known to be readily biodegradable substrates. Thus, in the absence of catabolic limitation (i.e., in the presence of excess easily degradable organic carbon), biotransformation of several targeted pharmaceuticals may be more expedient under anoxic versus aerobic conditions.

(ii) An increase in biodiversity might not translate into differences in microbial functionality if the microbial community presents sufficient biodiversity to begin with, that can saturate the possible effects (Johnson et al 2015a). While this effect was not observed for suspended biomass in full-scale WWTP (i.e., microbial communities were not sufficiently diverse to maximize the collective rate of multiple micropollutant biotransformation, Johnson et al., (2015a)), this may be different for biofilm systems that can already potentially harbor higher microbial diversity compared to suspended biomass (Stewart and Franklin, 2008). 
524 Overall, our results (at both global and system level) suggest that despite the general positive 525 association between microbial diversity and ecological activity (Cardinale, 2011; Emmett Duffy, 2009), 526 this association is not fully understood for microbial communities in biological wastewater treatment 527 regarding micropollutant biotransformation. On the other hand, additionally information could be 528 obtained by targeting a broader number of micropollutants.

529 Nonetheless, the relationships between microbial diversity and system stability and resilience in 530 wastewater treatment plant has been discussed (Lu et al., 2014), as a result of functional redundancy 531 (Briones and Raskin, 2003). Accordingly, it has been recommended that if two denitrifying 532 configurations perform equally efficiently, the configuration with higher functional diversity should be 533 preferentially selected to ensure higher system stability (Lu et al., 2014). 


\section{Conclusions}

The microbial communities of two pre-denitrifying MBBR systems operated in parallel in single- (U) and three-stage (S) configurations using pre-clarified wastewater as influent and native concentration of micropollutants were investigated during long-term operation.

- The decreasing gradient of organic carbon loading and availability (created through MBBR staging) led to an increase of $\alpha$-diversity of the microbial community (although not significant) within the three-stage system and an overall increased richness (ANOVA, $\mathrm{p}<0.05$ ) of the microbial community in the S configuration compared to $\mathrm{U}$.

- The microbial community became stable only after 200 days of operation, when the two configurations shared a core of OTUs such as Burkholderiales, Xanthomonadales, Flavobacteriales and Sphingobacteriales. The staged configuration (and in particular in the last stage MBBR, S3) selected for OTUs such as Candidate division WS6 and Deinococcales.

- S3 exposed to lower C-to-N ratios during continuous-flow operation exhibited the highest $(\mathrm{p}<0.05)$ abundance of atypical nos $Z$ gene and a lower nitrite reductase and nitrous reductase ration, suggesting a more effective $\mathrm{N}_{2} \mathrm{O}$ removal with respect to other reactor stages.

- Specific and collective bio- and re-transformation rate constants of the targeted pharmaceuticals positively correlated with specific denitrification rates and abundance of denitrifying genes (narG, nirS and nosZ typical), rather than biodiversity.

Overall, staging of MBBR systems under denitrifying conditions resulted in enhanced denitrification rate and increased microbial diversity compared to a single-stage configuration, although no major improvement was observed in the removal of the selected trace organic pharmaceuticals. 


\section{Acknowledgements}

561 This research was supported by MERMAID: an Initial Training Network funded by the People 562 Programme (Marie-Curie Actions) of the European Union's Seventh Framework Programme 563 FP7/2007-2013/under REA grant agreement n. 607492. The authors thank Luca Loreggian and Saverio 564 Conti for technical support.

565

566 
567

\section{References}

Alidina, M., Li, D., Ouf, M., Drewes, J.E., 2014. Role of primary substrate composition and concentration on attenuation of trace organic chemicals in managed aquifer recharge systems. J. Environ. Manage. 144, 58-66.

Arriaga, S., De Jonge, N., Lund Nielsen, M., Andersen, H.R., Borregaard, V., Jewel, K., Ternes, T.A., Lund Nielsen, J., 2016. Evaluation of a membrane bioreactor system as post-treatment in waste water treatment for better removal of micropollutants.

Barbosa, M.O., Moreira, N.F.F., Ribeiro, A.R., Pereira, M.F.R., Silva, A.M.T., 2016. Occurrence and removal of organic micropollutants: An overview of the watch list of EU Decision 2015/495. Water Res. 94, 257-279.

Birtel, J., Walser, J.-C., Pichon, S., Bürgmann, H., Matthews, B., 2015. Estimating Bacterial Diversity for Ecological Studies: Methods, Metrics, and Assumptions. PLoS One 10.

Braker, G., Zhou, J., Wu, L., Devol, A.H., Tiedje, J.M., 2000. Nitrite reductase genes (nirK and nirS) as functional markers to investigate diversity of denitrifying bacteria in pacific northwest marine sediment communities. Appl. Environ. Microbiol. 66, 2096-104. Briones, A., Raskin, L., 2003. Diversity and dynamics of microbial communities in engineered environments and their implications for process stability. Curr. Opin. Biotechnol. 14, 270-276.

Carballa, M., Omil, F., Lema, J.M., Llompart, M., García-Jares, C., Rodriguez, I., Gomez, M., Ternes, T., 2004. Behavior of pharmaceuticals, cosmetics and hor- mones in a sewage treatment plant. Water Res. 38 (12), $2918 \mathrm{e} 2926$.

Cardinale, B.J., 2011. Biodiversity improves water quality through niche partitioning. Nature 472, 869. 
Chaturvedi, R., Archana, G., 2012. Novel 16S rRNA based PCR method targeting Deinococcus spp. and its application to assess the diversity of deinococcal populations in environmental samples. J. Microbiol. Methods 90, 197-205.

Ciesielski, S., Kulikowska, D., Kaczowka, E., Kowal, P., 2010. Characterization of bacterial structures in a two-stage moving-bed biofilm reactor (MBBR) during nitrification of the landfill leachate. J. Microbiol. Biotechnol. 20, 1140-1151.

Dojka, M.A., Harris, J.K., Pace, N.R., 2000. Expanding the known diversity and environmental distribution of an uncultured phylogenetic division of bacteria. Appl. Environ. Microbiol. 66, $1617-21$.

Dojka, M., Hugenholtz, P., Haack, S., Pace, N., 1998. Microbial diversity in a hydrocarbon-and chlorinated-solvent-contaminated aquifer undergoing intrinsic bioremediation. Appl. Environ. Microbiol. 64, 3869-3877.

Emmett Duffy, J., 2009. Why biodiversity is important to the functioning of real-world ecosystems. Front. Ecol. Environ. 7, 437-444.

Escolà Casas, M.E., Chhetri, R.K., Ooi, G., Hansen, K.M.S., Litty, K., Christensson, M., Kragelund, C., Andersen, H.R., Bester, K., 2015. Biodegradation of pharmaceuticals in hospital wastewater by staged Moving Bed Biofilm Reactors (MBBR). Water Res. 83, 293-302.

Falås, P., Wick, A., Castronovo, S., Habermacher, J., Ternes, T.A., Joss, A., 2016. Tracing the limits of organic micropollutant removal in biological wastewater treatment. Water Res. 95, 240-249.

Fu, B., Liao, X., Ding, L., Ren, H., 2010. Characterization of microbial community in an aerobic moving bed biofilm reactor applied for simultaneous nitrification and denitrification. World J. Microbiol. Biotechnol. 26, 1981-1990.

Hallin, S., Throbäck, I.N., Dicksved, J., Pell, M., 2006. Metabolic profiles and genetic diversity of 
denitrifying communities in activated sludge after addition of methanol or ethanol. Appl. Environ. Microbiol. 72, 5445-5452.

Helbling, D.E., Johnson, D.R., Lee, T.K., Scheidegger, A., Fenner, K., 2015. A framework for establishing predictive relationships between specific bacterial 16S rRNA sequence abundances and biotransformation rates. Water Res. 70, 471-484.

Huston, M.A., 1994. Biological Diversity: the Coexistence of Species. Cambridge University Press.

Johnson, D.R., Helbling, D.E., Lee, T.K., Park, J., Fenner, K., Kohler, H.P.E., Ackermann, M., 2015 a. Association of biodiversity with the rates of micropollutant biotransformations among full-scale wastewater treatment plant communities. Appl. Environ. Microbiol. 81, 666-675.

Johnson, D.R., Lee, T.K., Park, J., Fenner, K., Helbling, D.E., 2015b. The functional and taxonomic richness of wastewater treatment plant microbial communities are associated with each other and with ambient nitrogen and carbon availability. Environ. Microbiol. 17, 4851-4860.

Johnson, D.R., Helbling, D.E., Men, Y., Fenner, K., 2015c. Can 613 meta-omics help to establish causality between contaminant biotransformations and genes or gene products? Environ. Sci. Water Res. Technol. 1, 272-278.

Joss, A., Zabczynski, S., Göbel, A., Hoffmann, B., Löffler, D., McArdell, C.S., Ternes, T. A., Thomsen, A., Siegrist, H., 2006. Biological degradation of pharmaceuticals in municipal wastewater treatment: Proposing a classification scheme. Water Res. 40, 1686-1696.

Kalyuzhnaya, M.G., Hristova, K.R., Lidstrom, M.E., Chistoserdova, L., 2008. Characterization of a novel methanol dehydrogenase in representatives of Burkholderiales: implications for environmental detection of methylotrophy and evidence for convergent evolution. J. Bacteriol. $190,3817-23$.

Khunjar, W. O.; Mackintosh, S. A.; Skotnicka-Pitak, J.; Baik, S.; Aga, D. S.; Love, N. G. Elucidating 
the relative roles of ammonia oxidizing and heterotrophic bacteria during the biotransformation of 17alpha-Ethinylestradiol and trimethoprim. Environ. Sci. Technol. 2011, 45 (8), 3605-3612. (14)

Li, D., Sharp, J.O., Saikaly, P.E., Ali, S., Alidina, M., Alarawi, M.S., Keller, S., Hoppe-Jones, C., Drewes, J.E., 2012. Dissolved organic carbon influences microbial community composition and diversity in managed aquifer recharge systems. Appl. Environ. Microbiol. 78, 6819-6828.

Li, D., Alidina, M., Ouf, M., Sharp, J.O., Saikaly, P., Drewes, J.E., 2013. Microbial community evolution during simulated managed aquifer recharge in response to different biodegradable dissolved organic carbon (BDOC) concentrations. Water Res. 47, 2421-30.

Lu, H., Chandran, K., Stensel, D., 2014. Microbial ecology of denitrification in biological wastewater treatment. Water Res. 64, 237-254.

Marzorati, M., Wittebolle, L., Boon, N., Daffonchio, D., Verstraete, W., 2008. How to get more out of molecular fingerprints: practical tools for microbial ecology. Environ. Microbiol. 10, 1571-81.

Naether, A., Foesel, B.U., Naegele, V., Wüst, P.K., Weinert, J., Bonkowski, M., Alt, F., Oelmann, Y., Polle, A., Lohaus, G., Gockel, S., Hemp, A., Kalko, E.K. V, Linsenmair, K.E., Pfeiffer, S., Renner, S., Schöning, I., Weisser, W.W., Wells, K., Fischer, M., Overmann, J., Friedrich, M.W., 2012. Environmental factors affect Acidobacterial communities below the subgroup level in grassland and forest soils. Appl. Environ. Microbiol. 78, 7398-406. Ofiteru, I.D., Lunn, M., Curtis, T.P., Wells, G.F., Criddle, C.S., Francis, C.A., Sloan, W.T., 2010. Combined niche and neutral effects in a microbial wastewater treatment community. Proc. Natl. Acad. Sci. 107, 1534515350.

Orellana, L.H., Rodriguez-R, L.M., Higgins, S., Chee-Sanford, J.C., Sanford, R.A., Ritalahti, K.M., Löffler, F.E., Konstantinidis, K.T., 2014. Detecting nitrous oxide reductase (NosZ) genes in soil metagenomes: method development and implications for the nitrogen cycle. MBio 5, e01193-14. 
Painter, M.M., Buerkley, M.A., Julius, M.L., Vajda, A.M., Norris, D.O., Barber, L.B., Furlong, E.T., Schultz, M.M., Schoenfuss, H.L., 2009. Antidepressants at environmentally relevant concentrations affect predator avoidance behavior of larval fathead minnows (Pimephales Promelas). Environ. Toxicol. Chem. 28, 2677.

Pal, L., Kraigher, B., Brajer-Humar, B., Levstek, M., Mandic-Mulec, I., 2012. Total bacterial and ammonia-oxidizer community structure in moving bed biofilm reactors treating municipal wastewater and inorganic synthetic wastewater. Bioresour. Technol. 110, 135e143

Pérez-Pantoja, D., Donoso, R., Agulló, L., Córdova, M., Seeger, M., Pieper, D.H., González, B., 2012. Genomic analysis of the potential for aromatic compounds biodegradation in Burkholderiales. Environ. Microbiol. 14, 1091-1117.

Pholchan, M.K., de Baptista, J.C., Davenport, R.J., Sloan, W.T., Curtis, T.P., 2013. Microbial community assembly, theory and rare functions. Front. Microbiol. 4, 1-9.

Plósz, B.G., 2007. Optimization of the activated sludge anoxic reactor configuration as a means to control nutrient removal kinetically. Water Res. 41, 1763-1773.

Plósz, B.G., Langford, K.H., Thomas, K. V, 2012. An activated sludge modeling framework for xenobiotic trace chemicals (ASM-X): assessment of diclofenac and carbamazepine. Biotechnol. Bioeng. 109, 2757-69.

Polesel, F., Torresi, E., Loreggian, L., Casas, M.E., Christensson, M., Bester, K., Plósz, B.G., 2017. Removal of pharmaceuticals in pre-denitrifying MBBR - Influence of organic substrate availability in single- and three-stage configurations. Water Res. 123, 408-419.

Price, M.N., Dehal, P.S., Arkin, A.P., 2009. FastTree: computing large minimum evolution trees with profiles instead of a distance matrix. Mol. Biol. Evol. 26, 1641-50.

Ribeiro, A.R., Afonso, C.M., Castro, P.M.L., Tiritan, M.E., 2013. Enantioselective HPLC analysis and 
biodegradation of atenolol, metoprolol and fluoxetine. Environ. Chem. Lett. 11, 83e90.

Roeleveld, P.J., Van Loosdrecht, M.C.M., 2002. Experience with guidelines for wastewater characterisation in The Netherlands. Water Sci. Technol. 45, 77-87.

Sanford, R.A., Wagner, D.D., Wu, Q., Chee-Sanford, J.C., Thomas, S.H., Cruz-García, C., Rodríguez, G., Massol-Deyá, A., Krishnani, K.K., Ritalahti, K.M., Nissen, S., Konstantinidis, K.T., Löffler, F.E., 2012. Unexpected nondenitrifier nitrous oxide reductase gene diversity and abundance in soils. Proc. Natl. Acad. Sci. U. S. A. 109, 19709-14.

Sathyamoorthy S, Chandran K, Ramsburg CA (2013) Biodegradation and cometabolic modeling of selected beta blockers during ammo- nia oxidation. Environ Sci Technol 47:12835-12843

Schloss, P.D., 2009. Introducing mothur: A Computational Toolbox for Describing and Comparing Microbial Communities. Abstr. Gen. Meet. Am. Soc. Microbiol. 109.

Stadler, L.B., Love, N.G., 2016. Impact of microbial physiology and microbial community structure on pharmaceutical fate driven by dissolved oxygen concentration in nitrifying bioreactors. Water Res. 104, 189-199.

Stewart, P.S., Franklin, M.J., 2008. Physiological heterogeneity in biofilms. Nat Rev Micro 6, 199210.

Sözen, S., Çokgör, E.U., Orhon, D., Henze, M., 1998. Respirometric analysis of activated sludge behaviour-II. Heterotrophic growth under aerobic and anoxic conditions. Water Res. 32, 476488.

Tan, D.T., Arnold, W.A., Novak, P.J., 2013. Impact of organic carbon on the biodegradation of estrone in mixed culture systems. Environ. Sci. Technol. 47, 12359-12365.

Torresi, E., Fowler, J.S., Polesel, F., Bester, K., Andersen, H.R., Smets, B.F., Plosz, B.G., Christensson, M., 2016. Biofilm thickness influences biodiversity in nitrifying MBBRs - 
Implications on micropollutant removal. Environ. Sci. Technol. 50, 9279-9288.

Torresi, E., Casas, M.E.C., Polesel, F., Pl, B.G., Bester, K., 2017. Impact of external carbon dose on the removal of micropollutants using methanol and ethanol in post-denitrifying moving bed biofilm reactors $108,95-105$.

Villemur, R., Juteau, P., Bougie, V., Ménard, J., Déziel, E., 2015. Development of four-stage moving bed biofilm reactor train with a pre-denitrification configuration for the removal of thiocyanate and cyanate. Bioresour. Technol. 181, 254-262.

Wells, G.F., Wu, C.H., Piceno, Y.M., Eggleston, B., Brodie, E.L., DeSantis, T.Z., Andersen, G.L., Hazen, T.C., Francis, C.A., Criddle, C.S., 2014. Microbial biogeography across a full-scale wastewater treatment plant transect: Evidence for immigration between coupled processes. Appl. Microbiol. Biotechnol. 98, 4723-4736.

Xia, S., Li, J., Wang, R., Li, J., Zhang, Z., 2010. Tracking composition and dynamics of nitrification and denitrification microbial community in a biofilm reactor by PCR-DGGE and combining FISH with flow cytometry. Biochem. Eng. J. 49, 370-378.

Yu, Y., Lee, C., Kim, J., Hwang, S., 2005. Group-specific primer and probe sets to detect methanogenic communities using quantitative real-time polymerase chain reaction. Biotechnol. Bioeng. 89, 670-9.

Zavaleta, E.S., Pasari, J.R., Hulvey, K.B., David Tilman, G., 2010. Sustaining multiple ecosystem functions in grassland communities requires higher biodiversity. Proc. Natl. Acad. Sci. 104, 14431446.

Zhang, Y., Ji, G., Wang, R., 2016. Drivers of nitrous oxide accumulation in denitrification biofilters with low carbon:nitrogen ratios. Water Res. 106, 79-85.

Ødegaard, H., 1999. The Moving Bed Biofilm Reactor. Water Environ. Eng. Reuse Water 250-305. 


\section{Tables}

Table 1. Results from qPCR targeting $16 \mathrm{~S}$ rRNA and functional genes in the four MBBRs (S1, S2, S3, U).

Values result from the average of the last four sampling days $(218,300,434$ and 471) after microbial community stabilization according to MWA. Values are reported with the corresponding standard deviation $(\mathrm{n}=8)$. Statistical

\begin{tabular}{|c|c|c|c|c|}
\hline & S1 & S2 & S3 & $\mathbf{U}$ \\
\hline $16 \mathrm{~S}$ rRNA & $2.13 \times 10^{11} \pm$ & $1.57 \times 10^{11} \pm$ & $7.24 \times 10^{10} \pm$ & $2.2 \times 10^{11} \pm$ \\
\hline (copies/g $\mathrm{g}_{\text {biomass }}$ ) & $44 \%$ & $16 \%$ & $7 \%^{(1)}$ & $19 \%$ \\
\hline $\operatorname{narG(\% )^{*}}$ & $48 \pm 20$ & $22 \pm 7^{(2)}$ & $53 \pm 22$ & $27 \pm 9$ \\
\hline $\operatorname{nirS}(\%)^{*}$ & $58 \pm 10$ & $54 \pm 9$ & $63 \pm 6$ & $64 \pm 9$ \\
\hline $\operatorname{nirK}(\%)^{*}$ & $8 \pm 4$ & $12 \pm 7$ & $11 \pm 5$ & $11 \pm 7$ \\
\hline nirS/nirK & $6.9 \pm 3$ & $8.3 \pm 3$ & $6.3 \pm 3$ & $10.9 \pm 11$ \\
\hline nosZ_typ $(\%)^{*}$ & $9 \pm 3$ & $9 \pm 1$ & $9 \pm 1$ & $9 \pm 2$ \\
\hline nosZ_atyp $(\%)^{*}$ & $6 \pm 1$ & $8 \pm 5$ & $15 \pm 8^{(3)}$ & $11 \pm 5$ \\
\hline nosZ_atyp/nosZ_typ & $0.72 \pm 0.23$ & $0.93 \pm 0.53$ & $1.60 \pm 0.71^{(3)}$ & $1.36 \pm 0.62$ \\
\hline (nirK+nirS)/ & $4.68+1.14^{(4)}$ & $3.86+0.59$ & $3.51+1.11$ & $3.96+0.70$ \\
\hline
\end{tabular}

(1) significantly lower than S1 and U (95\% confidence interval)

735 (2) significantly lower than S1 and S3 (95\% confidence interval)

736 (3) significantly higher than S1 and S2 (95\% confidence interval) 

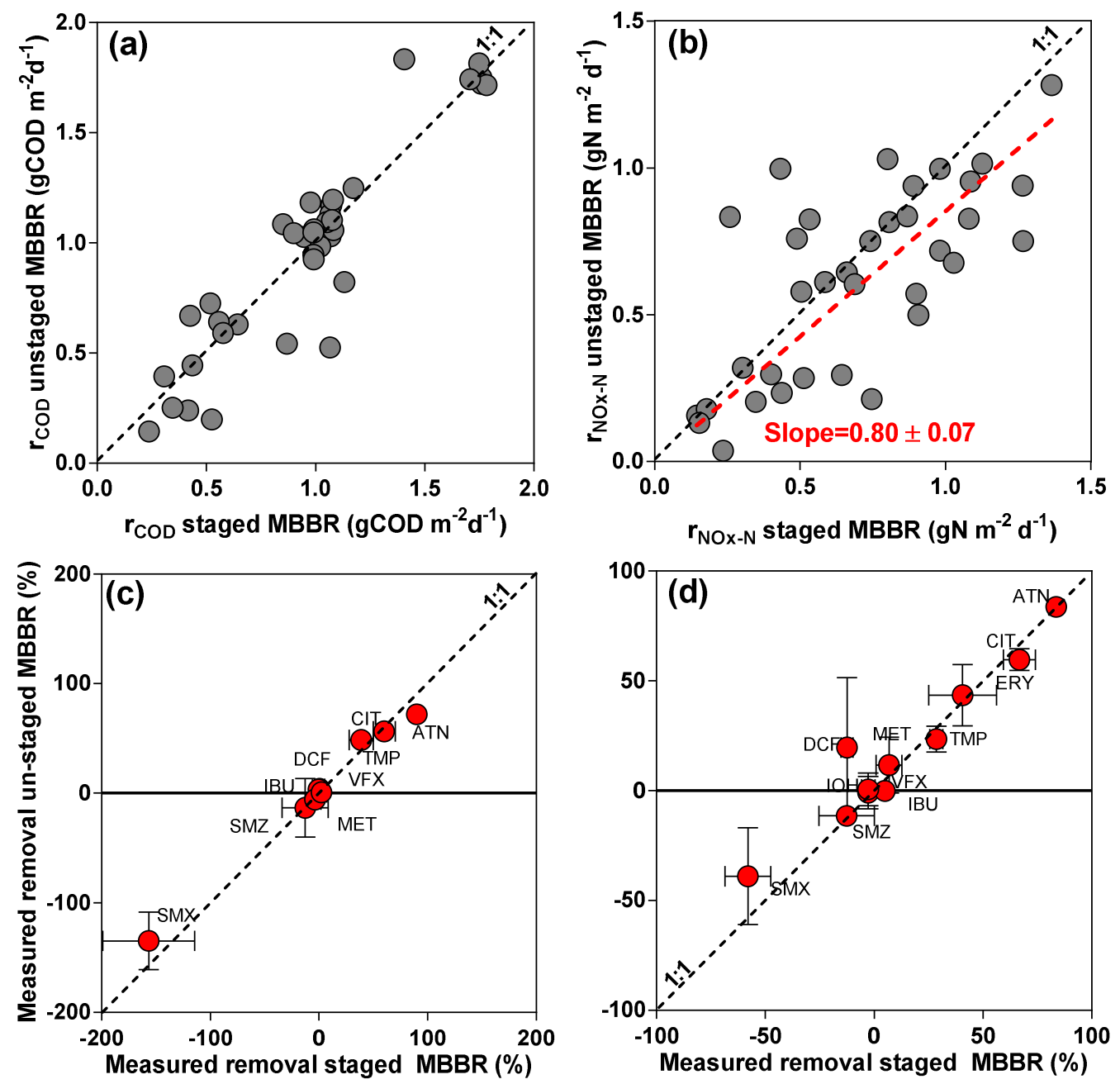

740 Figure 1. Measured data from continuous-flow operation. Comparison between COD removal rates $\left(\mathrm{r}_{\mathrm{COD}}\right.$, $\left.741 \mathrm{gCOD} \mathrm{d}^{-1} \mathrm{~m}^{-2}\right)$ (a) and denitrification rate $\left(\mathrm{r}_{\mathrm{NOx}-\mathrm{N}}, \mathrm{gN} \mathrm{m}^{-2} \mathrm{~d}^{-1}\right)$ (b) in the three-(S) and single-stage (U) MBBR 742 configuration $(n=40)$; comparison between micropollutant removal $(\%)$ in $S$ and $U$ in the first (c, 100 days of 743 operation) and second (d, 470 days of operation) campaigns (Polesel et al., 2017). Dashed red line in (b) shows 744 linear regression (slope $0.80 \pm 0.07, \mathrm{p}<0.001$ ). Abbreviations: $\mathrm{ATN}=$ atenolol; $\mathrm{CIT}=$ citalopram; $\mathrm{TMP}=$ 
745 trimethoprim; DCF = diclofenac; IBU = ibuprofen; MET = metoprolol; SMX = sulfamethoxazole; SMZ = 746 sulfamethizole; VFX = venlafaxine; ERY = erythromycin; IOH = iohexol.
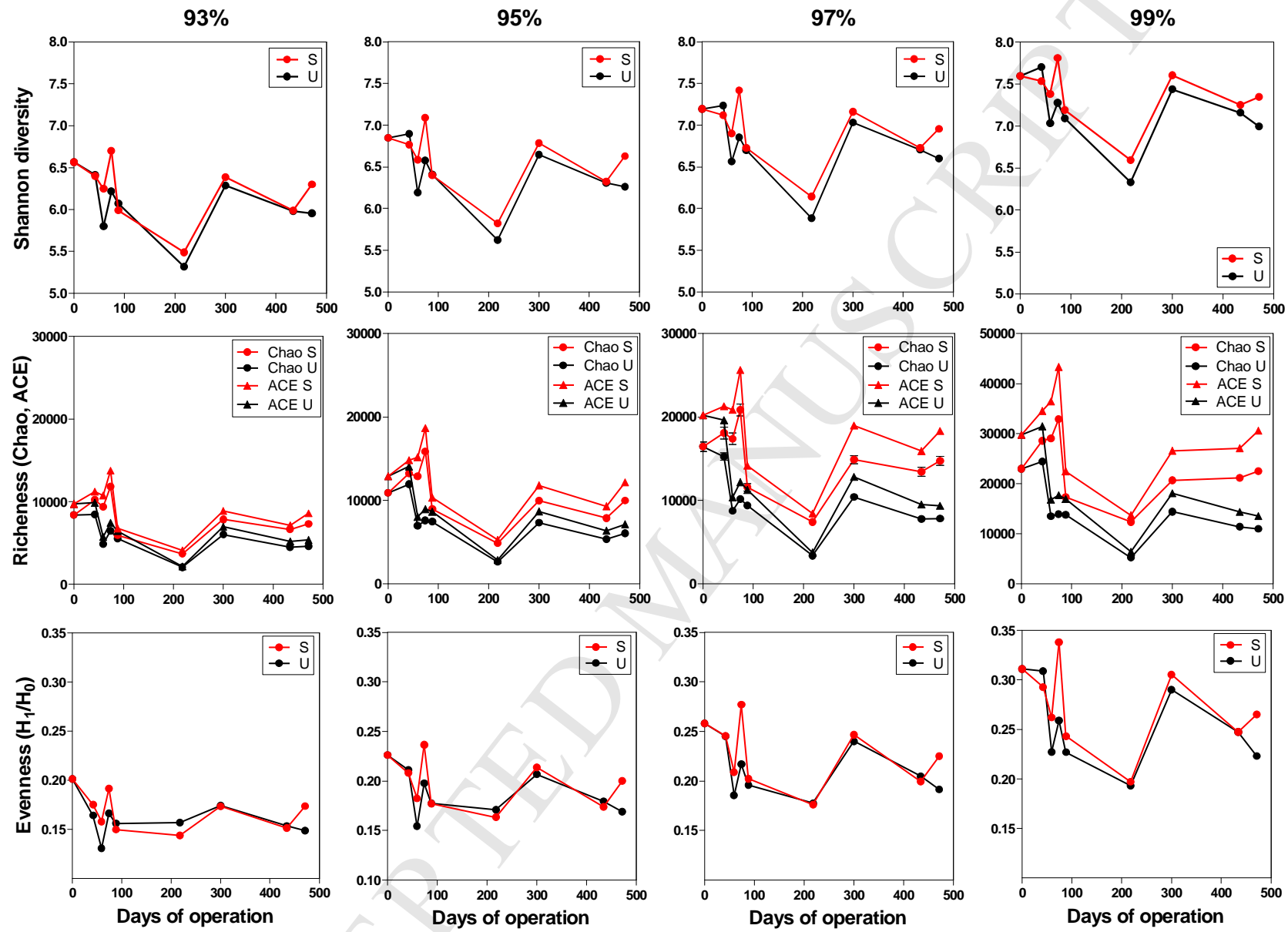

749 Figure 2. Shannon, richness (Chao and ACE) and evenness $\left(\mathrm{H}_{1} / \mathrm{H}_{0}\right)$ indices measured at different time points for

750 the three-(S) and single-stage (U) MBBR configuration at 93, 95, $9799 \%$ of sequencing similarity. Error bars

751 define standard errors. 


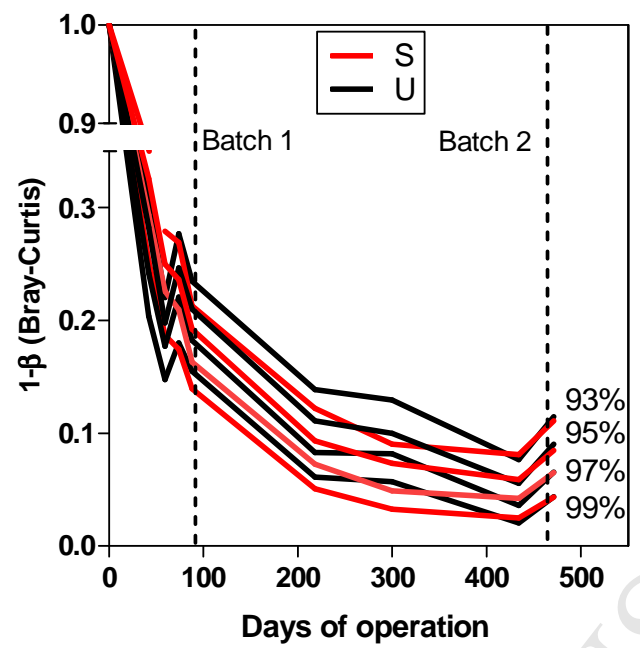

753

754 Figure 3. Moving window analysis (MWA) using reciprocal of Bray-Curtis indices ( $\beta$ ) from the initial biofilm 755 inoculum measured at different sequence similarity (93-99\%) for S and U over 471 days of operation. 

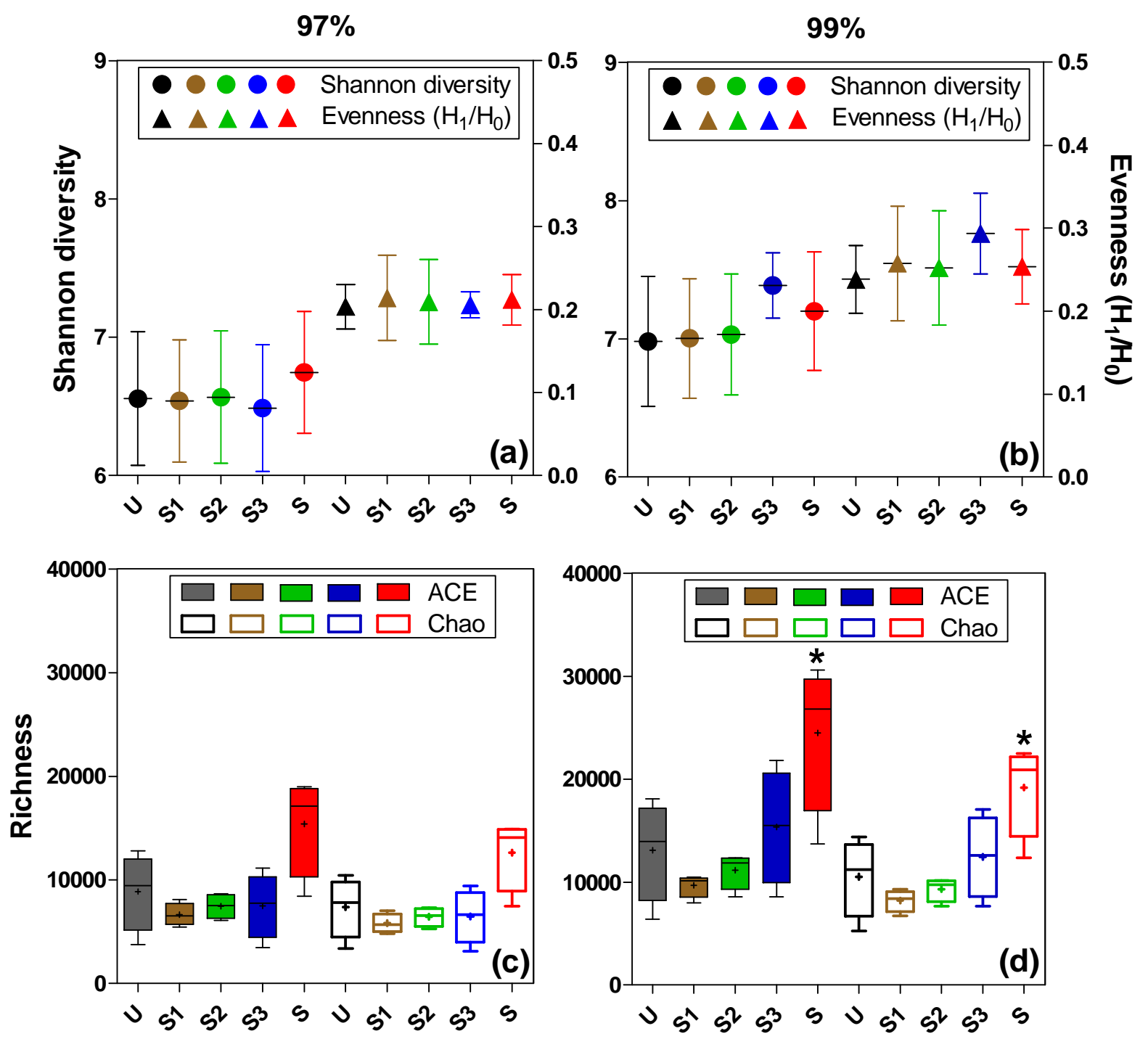

758 Figure 4. Averaged values of Shannon diversity, evenness, ACE and Chao indices after 200 days of operation 759 ( $\mathrm{n}=4)$ at $97 \%$ (a, c) and 99\% (b, d) sequence similarity cut-offs for the three stages MBBR at local (S1, S2, S3) 760 and system (S) level and the single stage system (U). Asterisks indicate significance difference (ANOVA, $761 \mathrm{p}<0.05)$. Mean is shown as + . 


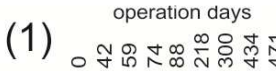

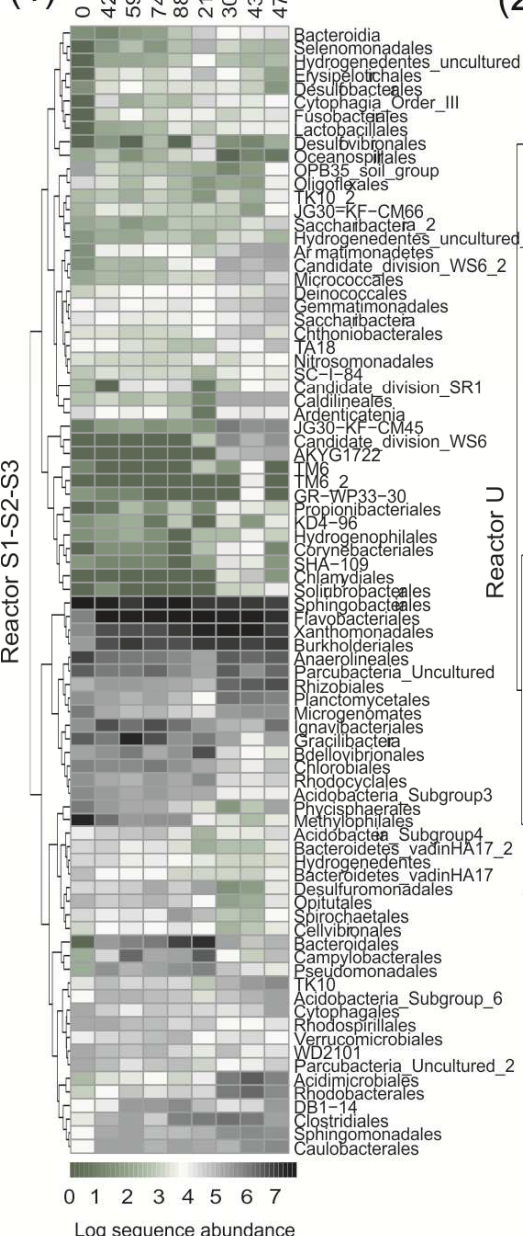

operation days

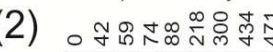

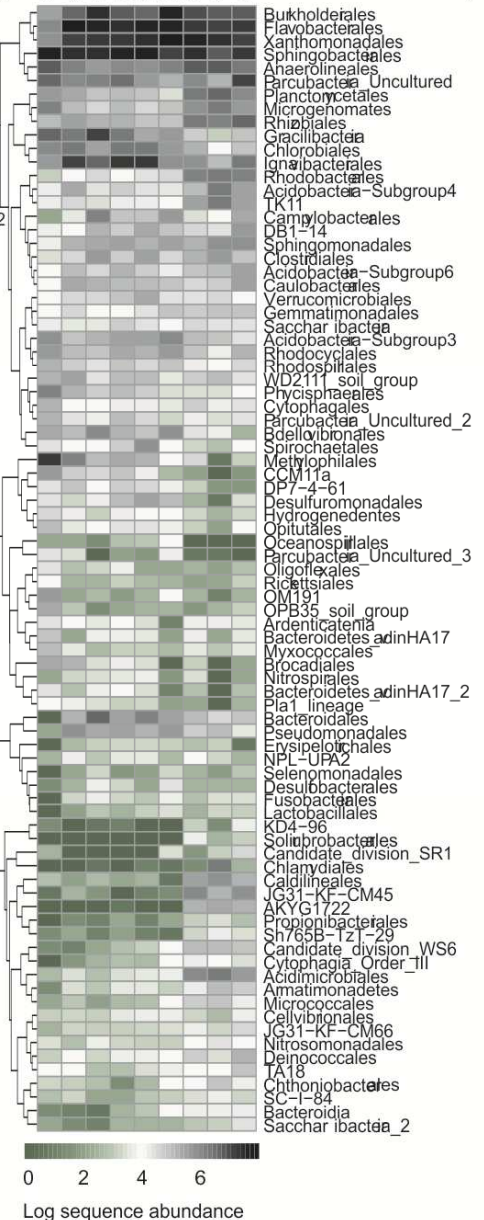
Log sequence abundance
(3)

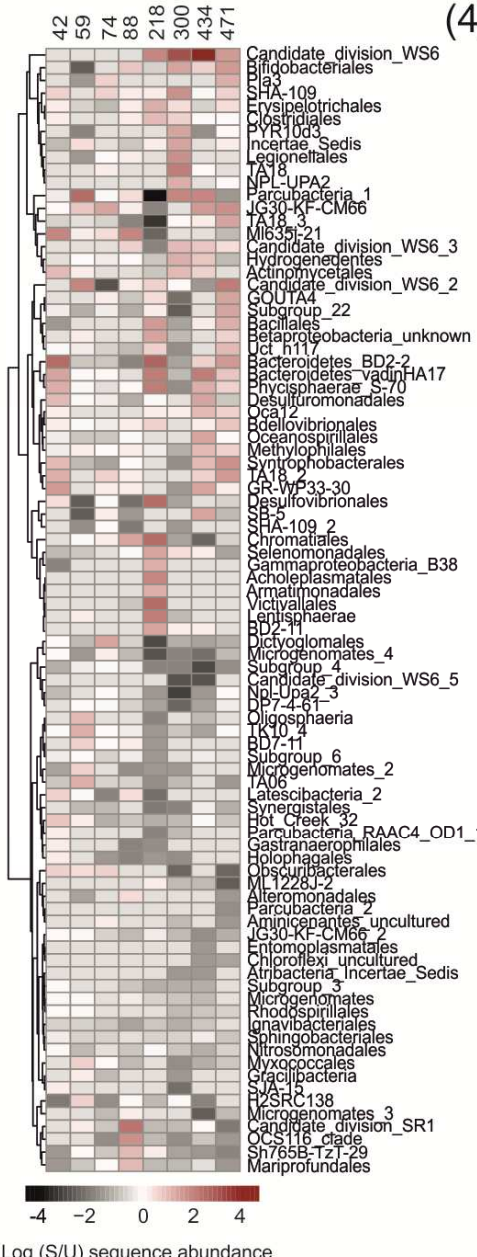

operation days

4)

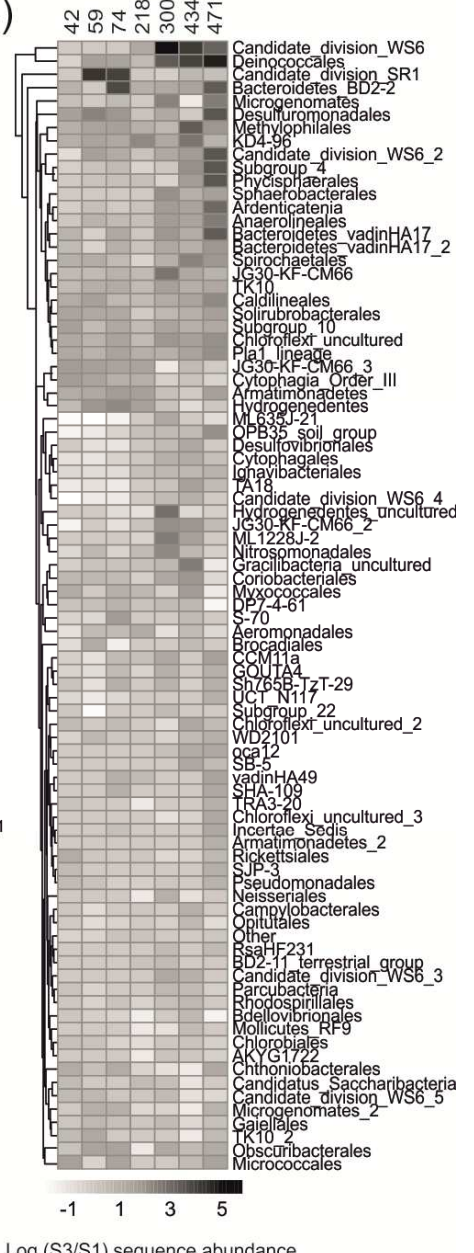

$\log (\mathrm{S} 3 / \mathrm{S} 1)$ sequence abundance

762

763 Figure 5. Heatmaps of the 100 most abundant order level taxa in the staged MBBR, S (a) and un-staged MBBR, U (b). The most shifted 

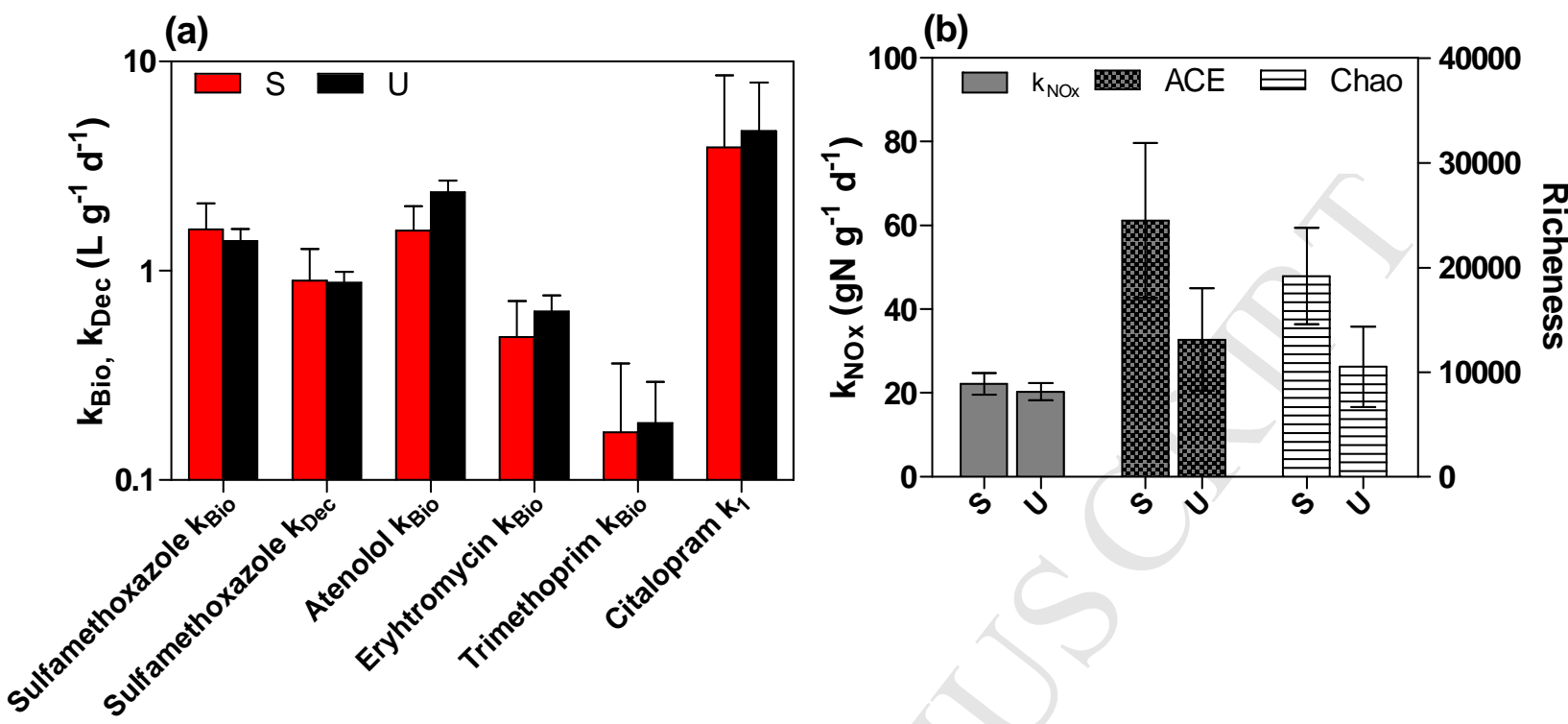

769 Figure 6. Biotransformation and retransformation rate constants $\mathrm{k}_{\mathrm{Bio}}$ and $\mathrm{k}_{\mathrm{Dec}}\left(\mathrm{L} \mathrm{g}^{-1} \mathrm{~d}^{-1}\right)$ for each micropollutant 770 (a) and specific denitrification rate $\left(k_{N O x}\right), \mathrm{ACE}$ and Chao indices (b) calculated at system level for S for U 771 (Polesel et al., 2017) MBBR in Batch 2. Abbreviations: $\mathrm{k}_{1}$, biotransformation rate constant of enantiomer 1. 


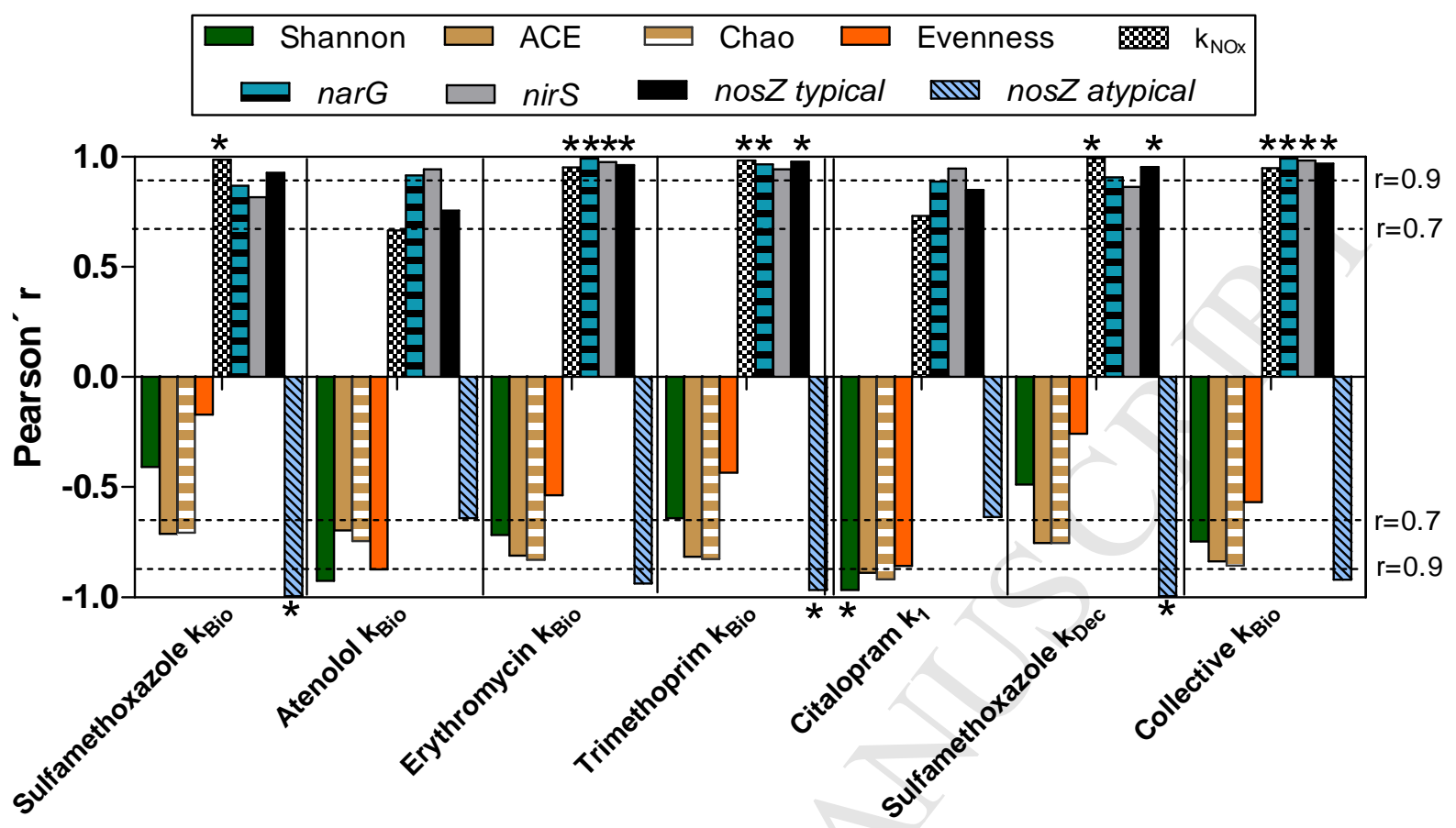

774

775

776

777

778

779

780

Figure 7. Pearson's coefficient $(r)$ of the correlation between biotransformation $\left(k_{\mathrm{Bio}}\right)$, retransformation $\left(\mathrm{k}_{\mathrm{Dec}}\right)$ of micropollutant, collective $\mathrm{k}_{\mathrm{Bio}}$ with Shannon biodiversity, richness (ACE and Chao), evenness indices ( at 99\% sequences similarity) and specific denitrification rate $k_{N O x}\left(\mathrm{mgN} \mathrm{g}^{-1} \mathrm{~d}^{-1}\right)$ for Batch 2 . Asterisks indicate significance (ANOVA, $\mathrm{p}<0.05)$. 


\section{Highlights}

- Microbial composition and diversity in single- and three stage MBBR investigated

- Reactor staging increased overall microbial richness and evenness in staged MBBR

- Microbial diversity increased with decreasing carbon loading in staged MBBR

- Biotransformation of pharmaceuticals positively correlated with denitrifying genes abundance

- Biotransformation of pharmaceuticals did not correlate with microbial diversity 